PILOT STUDIES FOR IN VIVO

BONE ALUMINUM MEASUREMENTS 


\title{
PILOT STUDIES FOR IN VIVO \\ BONE ALUMINUM MEASUREMENTS
}

by

STÉPHANIE PALERME, B.Sc.

\author{
A Thesis \\ Submitted to the School of Graduate Studies \\ in Partial Fulfilment of the Requirements \\ for the Degree \\ Master of Science \\ (Medical Physics)
}

McMaster University

August 1993 
MASTER OF SCIENCE (1993)

(Medical Physics)
MCMASTER UNIVERSITY

Hamilton, Ontario

TITLE: Pilot Studies for In Vivo Bone Aluminum Measurements AUTHOR: Stéphanie Palerme, B.Sc. (University of Ottawa) SUPERVISOR: Dr. D.R. Chettle NUMBER OF PAGES: ix, 98 


\begin{abstract}
Excess aluminum has been linked to such diseases as dialysis encephalopathy syndrome and osteodystrophy, in renal dialysis patients. Though the causality relation has not yet been confirmed, aluminum has also been associated with Alzheimer's disease.

Aluminum is thought to be stored in bones, and a measure of its deposition should correlate with its total bioaccumulation. To date, only bone biopsies and desferrioxamine tests are available for such measurements. Neutron activation analysis (NAA) has been studied as a non-invasive technique for measuring bone aluminum. Two neutron beam ports from the McMaster nuclear reactor and the $\mathrm{KN}$ accelerator have been compared as possible thermal neutron sources. Resin-based phantoms, physiologically resembling a hand, were irradiated using the reactor based neutron source. From the results, a minimum detection limit (MDL) of aluminum in bone was obtained. An Andersson-Braun remmeter measured the dose delivered to the phantoms, due to the radiation exposure. The hand dose equivalent combined with the MDL, in this study, are compared to the results of previous NAA studies. The goal of this study is to measure low aluminum stores In Vivo, while delivering a low dose with respect to natural background levels.
\end{abstract}




\section{ACKNOWLEDGEMENTS}

Throughout this two year study, a great number of people have aided, influenced and enriched both my personal and academic life. To all these good Samaritans, I give you my most sincere thanks.

I would like to first thank my supervisor, Dr. David R. Chettle, who motivated me into entering the field of trace element detection (a snowless field may I add !), and thus was responsible for its downfall. I would also like to convey my appreciation to the members of my supervisory committee, Drs. C.E. Webber, W.V. Prestwich, and T.J. Kennett. Their near-unlimited source of knowledge, especially in the programming field, contributed immensely to this work.

Thanks to John Avelar for his continuous patience when it came to opening and closing (times too numerous to mention) the beam cave, to Alice Pidruczny for her work in obtaining last minute data, and to the reactor operators and staff, especially Mike Butler, for their help.

These two years were made tolerable by the encouragement and support of my family, most particularly my mother. A few more care packages would have been appreciated, but I shall say no more.

Last but not least, I must mention the influence my colleagues and 
friends had on my stay. First, I thank my officemates Ricky, for listening and perhaps understanding; Dave, the computer god, for not letting me quit when I really wanted to; and Joe and Rick whose points-of-view were missed.

The most influential and thus difficult group to acknowledge are my dear friends and housemates from the Mansion. Pete, Marlene, Gord, Mark, Heather, and Pat have all contributed to the startling changes in myself, and permitted me to achieve not only an M.Sc, but inner peace. Lastly, I would like to thank Chris for showing me how to laugh with others as well as at myself (Wacka Wacka). I hope you will keep reminding me of this lesson. 


\section{TABLE OF CONTENTS}

ABSTRACT $\ldots \ldots \ldots \ldots \ldots \ldots \ldots \ldots \ldots \ldots \ldots \ldots \ldots \ldots$ iii ACKNOWLEDGEMENTS $\ldots \ldots \ldots \ldots \ldots \ldots \ldots \ldots \ldots \ldots$ iv

TABLE OF CONTENTS $\ldots \ldots \ldots \ldots \ldots \ldots \ldots \ldots \ldots \ldots \ldots$ vi

LIST OF FIGURES $\ldots \ldots \ldots \ldots \ldots \ldots \ldots \ldots \ldots \ldots \ldots$ viii

LIST OF TABLES $\ldots \ldots \ldots \ldots \ldots \ldots \ldots \ldots \ldots \ldots \ldots \ldots \ldots \ldots$ ix

Chapter I Introduction

1.1 On the Subject of Aluminum $\ldots \ldots \ldots \ldots \ldots \ldots \ldots \ldots \ldots$

1.2 In Vitro Methods of Measuring Aluminum $\ldots \ldots \ldots \ldots \ldots \ldots 4$

1.3 Feasibility of In Vivo Measurements of Aluminum $\ldots \ldots \ldots \ldots 6$

1.4 McMaster Study of Aluminum in Bone . . . . . . . . . . 12

Chapter II Materials and Methods

2.1 Detection System $\ldots \ldots \ldots \ldots \ldots \ldots \ldots \ldots \ldots \ldots \ldots \ldots \ldots$

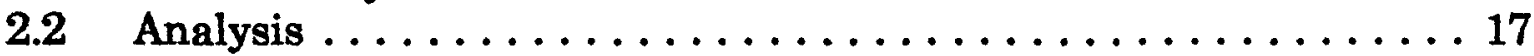

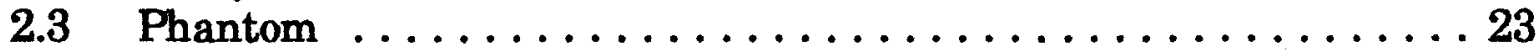

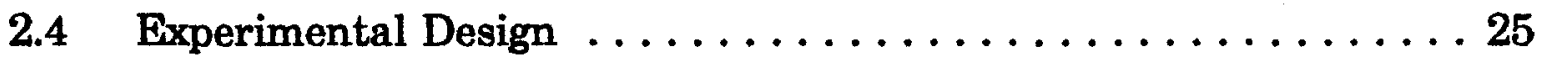

Chapter III Comparison of Neutrons Sources

$3.1 \quad$ Neutron Sources $\ldots \ldots \ldots \ldots \ldots \ldots \ldots \ldots \ldots \ldots 29$

3.2 Comparison of Thermal Neutron Output . . . . . . . . . 39

Chapter IV Calibration Curve and Minimum Detection Limit

4.1 Initial Experiments $\ldots \ldots \ldots \ldots \ldots \ldots \ldots \ldots \ldots \ldots$

4.2 Calibration Curve and Minimum Detection Limit ........ 56

4.3 Aluminum Impurities and Phosphorous Interference

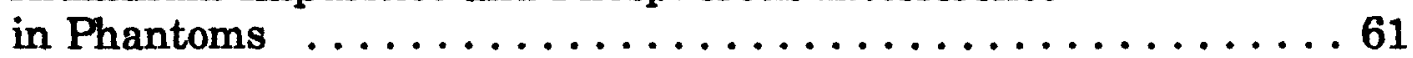

Chapter V Dose Measurements

5.1 Description of the Andersson-Braun Remmeter $\ldots \ldots \ldots \ldots 68$ 
5.2 Dosimetry Protocol $\ldots \ldots \ldots \ldots \ldots \ldots \ldots \ldots \ldots \ldots \ldots \ldots \ldots \ldots$

5.3 Dosimetry Results ..................... 72

Chapter VI Further Work I: Activation Foils

6.1 Materials and Methods $\ldots \ldots \ldots \ldots \ldots \ldots \ldots$

6.2 Initial Experimental Results $\ldots \ldots \ldots \ldots \ldots \ldots$

Chapter VII Further Work II: Phantom Irradiation

7.1 Phantom Improvements $\ldots \ldots \ldots \ldots \ldots \ldots$

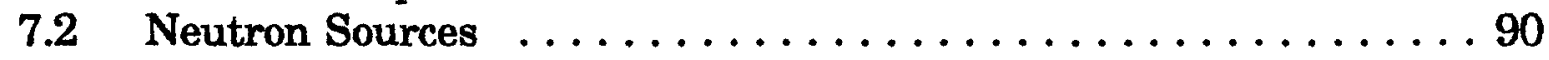

7.3 Dosimetry ......................... 92

REFERENCES AND BIBLIOGRAPHY . . . . . . . . . . . . . 94 


\section{LIST OF FIGURES}

Figure 2.1: Relation Between Peak Width Squared and

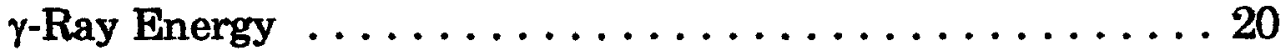

Figure 2.2: Spectrum of a Resin Hand Phantom ( $0.5 \mathrm{mg}$ of Added $\mathrm{Al}) \ldots \ldots \ldots \ldots \ldots \ldots \ldots \ldots \ldots \ldots \ldots$

Figure 3.1: Schematic of the McMaster Nuclear Reactor Beam Ports .. 30

Figure 3.2: Radiation Weighting Factors for Neutrons $\ldots \ldots \ldots \ldots 32$

Figure 3.3: Beam Port 4 Diagram $\ldots \ldots \ldots \ldots \ldots \ldots \ldots \ldots \ldots \ldots$

Figure 3.4: KN-Accelerator Diagram . . . . . . . . . . . . 35

Figure 3.5: Comparison of Neutron Sources: Beam Port 2 . . . . . 40

Figure 3.6: Comparison of Neutron Sources: Beam Port $4 \ldots \ldots \ldots .41$

Figure 3.7: Comparison of Neutron Sources: KN-Accelerator . . . . . 42

Figure 4.1: Typical Background Spectrum $\ldots \ldots \ldots \ldots \ldots \ldots \ldots 52$

Figure 4.2: Typical Decay of Calcium Peak with Time $\ldots \ldots \ldots \ldots \ldots 5$

Figure 4.3: Spectra for Two Phantoms of Widely Different Al Content . 57

Figure 4.4: Calibration Curve $\ldots \ldots \ldots \ldots \ldots \ldots \ldots \ldots \ldots$

Figure 4.5: Corrected Calibration Curve $\ldots \ldots \ldots \ldots \ldots \ldots \ldots 66$

Figure 5.1: Snoopy Positioning in Beam Port $4 \ldots \ldots \ldots \ldots \ldots \ldots 71$

Figure 5.2: Snoopy Dose Equivalent Curve $\ldots \ldots \ldots \ldots \ldots \ldots \ldots 74$

Figure 5.3: Snoopy Dose Equivalent Line $\ldots \ldots \ldots \ldots \ldots \ldots \ldots 76$ 


\section{LIST OF TABLES}

Table 3.1: Relative Flux Intensities of Neutron sources . . . . . . . . 45

Table 4.1: Background Al Peak Measurements . . . . . . . . . . . 49

Table 4.2: Aluminum and Calcium Peaks from Phantom Spectra . . . . . . . . . . . . . . . . . . . 59

Table 4.3: Determination of $\mathrm{Al}$ Impurity and P Interference . . . . . 64

Table 5.1: Comparison of Hand Doses and Minimum Detection Limits . . . . . . . . . . . . . . . . 80

Table 6.1: Neutron Flux from Activation Foil Data . . . . . . . . 85 


\section{Chapter I}

\section{Introduction}

\subsection{On the Subject of Aluminum}

The topic of aluminum and its interaction with humans is becoming an increasingly important issue. Aluminum is one of the most common element in the earth's crust and also enjoys an omnipresence in our everyday lives. The average North American ingests 3.8 to $51.6 \mathrm{mg} \mathrm{Al}$ daily [1]. Baking soda, antacid tablets, aspirin, anti-perspirants, tea and cooking utensils all contain some form of aluminum. This element also finds its way into drinking water. Lakes and streams can become contaminated with aluminum, due to acid rain which causes this metal to leach out of rocks. Furthermore, aluminum is added to drinking water as part of the purification process [1].

Aluminum is a known neurotoxin, but naturally has a low absorption in the gastro-intestinal tract. However, the percentage of aluminum that actually reaches the bloodstream remains a question. Certain compounds are absorbed better than others, depending on their ingested form. Absorption can also be affected by the presence or absence of other compounds. For example, the presence of iron, phosphate and fluoride decrease aluminum absorption, 
whereas maltol, citric acid, and parathyroid hormone or dietary vitamin $D$, as well as deficiencies in calcium, iron and zinc, increase absorption [33].

The main point is that the metabolism of all aluminum compounds is not known. Questions on the toxicity of the levels of aluminum, to which humans are routinely exposed, remain unanswered. Imposing limitations on the intake of this element could be a possibility.

Some illnesses have been linked to excess aluminum in the body. For instance, dialysis osteomalacia, renal osteodystrophy and dialysis encephalopathy syndrome (DE) have been shown to be associated with the excess aluminum intake of patients on long-term dialysis [45]. Previously, the haemodialysis fluid was based on drinking water, thus inputting its aluminum content directly into the blood stream. Furthermore, patients with kidney failure take aluminum-based phosphate binders as medication. The first two aluminum-related problems are types of bone deformations due to the deposition of aluminum during skeletal repair. DE is a form of dementia not unlike Alzheimer's disease; however, it can be reversible if caught in time.

The main organs affected by aluminum toxicity are the brain and the bones, though the liver can also have a high capacity to accumulate this element [46]. In bones, aluminum impairs skeletal mineralization and diminishes bone cell activity [19]. The main long term storage organ for aluminum is thought to be bone; however, substantial quantities may be 
sequestered as alumino-silicates in lungs.

The link between the etiology of Alzheimer's disease (AD) and aluminum is still controversial. Does excess aluminum, accumulated over a lifetime, travel to certain brain regions, where it has been found in some studies [7], and cause the dementia? Or does some deficiency in the blood-brain barrier, due to the disease, allow aluminum to enter the brain? The causality relationship is not yet clear. A study by Martyn at al. [31] showed that the risk of $\mathrm{AD}$ was 1.5 times greater in districts where the mean aluminum concentration in drinking water exceeded $0.11 \mathrm{mg} /(0.11 \mathrm{ppm})$ than in districts where the concentration was less than $0.01 \mathrm{mg} /$. Three other separate studies $[12,14,37]$ have demonstrated a link between an elevated aluminum concentration in drinking water and an increase in aluminum absorption and retention.

The connections between aluminum and $\mathrm{AD}$ give rise to concerns on the safety of long term "normal" aluminum exposures. However, groups with an occupational exposure to aluminum, such as airplane or automobile industry workers, would be at a greater risk if any aluminum toxicity exists. Gold and uranium miners in Northern Ontario, between the years 1944 to 1979, are of particular interest. These miners inhaled "McIntyre powder" for 10 minutes, at the start of each shift, before going down the mines. This powder was a finely ground aluminum and aluminum oxide mixture which was thought, from 
scientific evidence at the time [10], to act as a prophylactic agent against silicosis lung disease. In a recent survey of a group of these miners, to determine if this aluminum exposure had caused any ill effects, no resulting neurological disorders were diagnosed but the miners performed less well on cognitive state tests than a reference group [39].

Measurements of aluminum body burdens and of bioaccumulation changes with time are important factors needed to clarify the aluminum questions. Serum, following desferrioxamine provoked chelation [6], and bone samples [25] can be used to measure aluminum stores. The brain is also a relevant target organ, but samples may be inaccessible to direct measurements.

\subsection{In Vitro Methods of Messuring Aluminum}

Invasive methods are so far the only techniques available for measuring aluminum in patients. Bone biopsies are a common method. A small core of bone is extracted and analyzed by atomic absorption spectroscopy (AAS).

When serum samples are measured for aluminum, the levels are low and bear no clear relation to exposure [15]. The drug desferrioxamine may be administered to patients as part of an aluminum mobilization test. Desferrioxamine gives temporarily raised aluminum levels in serum, 
presumably due to the leaching of aluminum from the body stores, perhaps bone. Furthermore, the results show a correlation with exposure [6]. In higher doses, desferrioxamine can be administered as a chelating treatment to reduce body stores, and perhaps reduce or prevent the possible toxic effects of aluminum [8]. However, this treatment is controversial. Not all studies agree on the efficacy of the method, and it has possible serious side effects including nausea and weight loss [29]. The desferrioxamine mobilization test can also have possible side effects, but less severe than those from the treatment.

Brain samples from people who died from $\mathrm{AD}$ are also analyzed in order to determine the aluminum content in various sections of the brain.

Metabolic information on aluminum absorption can be obtained by administering an ${ }^{27} \mathrm{Al}$ solution with a small fraction of the radioactive isotope ${ }^{26} \mathrm{Al}$, which will act as a tracer $[2,9,26,47]$. After given time periods, samples of tissue that will be targeted by aluminum are taken. Total aluminum levels can be measured by $\mathrm{AAS}$ and an isotope ratio of ${ }^{26} \mathrm{AV}{ }^{27} \mathrm{Al}$ is obtained by accelerator mass spectroscopy (AMS) using a tandem Van De Graff accelerator. Thus, the net absorbed aluminum can be calculated as a function of time since exposure, and of tissue type.

The main disadvantage of invasive methods is the opportunity for contact with aluminum impurities, naturally present in our surroundings. The more the samples are handled, the greater the risk of contamination. 
Furthermore, the samples can only be very small, thus the low aluminum levels expected will have large uncertainties. For large scale studies where a group is monitored for aluminum burdens, in vitro methods are not feasible. The solution would appear to be non-invasive techniques.

\subsection{Feasibility of In Vivo Measurements of Aluminum}

A practical and feasible technique for non-invasive measurements of aluminum in bones is neutron activation analysis (NAA). A study by Bogdanovich et al. [4] tried to provide justification for NAA measurements of Al. Instrumental neutron activation analysis performed on bone samples was shown to agree within $10 \%$ on the level of aluminum when compared to the results of AAS. However, in this study, aluminum levels below $70 \mu \mathrm{g}$ per $\mathrm{g}$ apatite (ie. normal range) could not be reliably determined.

The method consists of exposing a part of the body to a beam of neutrons, causing the ${ }^{27} \mathrm{Al}(\mathrm{n}, \gamma){ }^{28} \mathrm{Al}$ reaction. ${ }^{28} \mathrm{Al}$ decays with a half-life of 2.3 minutes, releasing a $\gamma$-ray of $1.78 \mathrm{MeV}$. To reduce the effective dose given to the body, an extremity such as the hand is chosen as the site of irradiation. After exposure to the beam, a spectrum of decaying activated isotopes is measured by $\mathrm{NaI}(\mathrm{TI})$ detectors. The area under the ${ }^{28} \mathrm{Al}$ peak gives a measure of the aluminum present in the bones of the hands, which can then be scaled 
up to give the total skeletal burden. ICRP 23 [22] predicts for the skeletal system of reference man $21 \mathrm{mg}$ of $\mathrm{Al}$. Since $1.5 \%$ of the skeleton is in one hand, for reference man, approximatively $0.3 \mathrm{mg}$ of $\mathrm{Al}$ is normally expected to be measured. To compensate for the variation in the subject's hand size, positioning, non-uniformities in neutron irradiation and detector sensitivity, the aluminum quantity can be normalized to the calcium quantity measured from the ${ }^{48} \mathrm{Ca}(\mathrm{n}, \gamma){ }^{49} \mathrm{Ca}$ reaction. For a reference group, $25 \mu \mathrm{g}$ of $\mathrm{Al}$ per $\mathrm{g}$ of $\mathrm{Ca}$ would be expected in the hand. The reactions ${ }^{31} \mathrm{P}(\mathrm{n}, \alpha)^{28} \mathrm{Al}$ and ${ }^{28} \mathrm{Si}(\mathrm{n}, \mathrm{p}){ }^{28} \mathrm{Al}$, with thresholds of 1.95 and $4.0 \mathrm{MeV}$ respectively, can cause interferences with the ${ }^{27} \mathrm{Al}$ activation, if the neutron beam energies are not below the cutoff levels.

A variety of research groups have conducted experiments measuring normal to elevated levels of aluminum. First, Williams et al. [44], in 1980, used two sealed-tube $14 \mathrm{MeV}$ neutron generators in order to conduct total-body neutron activation analysis (TBNAA) on a group of patients on dialysis showing symptoms of dialysis encephalopathy syndrome (DE), a dialysis group not showing these symptoms, and a control group not on dialysis. Patients were characterized as having DE if they showed a characteristic EEG and serum $\mathrm{Al}$ in excess of $350 \mu \mathrm{g} /$. The dose delivered to the patients in the activation procedure was $10 \mathrm{mSv}$ at the body surface. In comparison, the annual dose due to background radiation is approximately 2 to $3 \mathrm{mSv}$. This exemplifies a difficulty in using in vivo methods. Since the experiments are 
conducted on volunteers the dose received by the patient must be minimized. Thus researchers are faced with a compromise between lowering the dose due to the procedure and maintaining the quality of the measurements.

As previously mentioned, the activation of ${ }^{27} \mathrm{Al}$ and ${ }^{31} \mathrm{P}$ are indistinguishable in the detected spectra. In the Williams et al. study, it was determined that $1 \mathrm{~g}$ of $\mathrm{Al}$ gave the same response as $8 \mathrm{~g}$ of $\mathrm{P}$. This gives a measure of the thermal "purity" of the neutron beam. The final results showed that patients with symptoms of DE were not statistically different in their aluminum burdens from renal patients without the symptoms.

The second approach to NAA was at Brookhaven, where Ellis et al. [13] determined aluminum burdens using TBNAA. Moderated fast neutrons produced from fourteen $50 \mathrm{Ci}{ }^{238} \mathrm{Pu}, \mathrm{Be}$ sources irradiated phantoms for 5 minutes, followed by a 3 minute transfer time and a 15 minute counting period, using a whole body counter. In this case $1 \mathrm{~g}$ of $\mathrm{Al}$ gave the same response as $68.3 \mathrm{~g}$ of $\mathrm{P}$. Aluminum peaks were clearly evident in the spectra from the irradiations of nine asymptomatic renal patients.

A second study by this group investigated neutron activation of the hand. The source was a collimated therma/epithermal neutron beam of flux $1.36 \times 10^{7} \mathrm{n} / \mathrm{cm}^{2} / \mathrm{s}$, from the medical research reactor. At these energies, phosphorus interference is negligible, equating to $4 \mu \mathrm{gl}$ per $\mathrm{g}$ bone, or an $\mathrm{Al}$ to $\mathrm{P}$ ratio of 12,500 to 1 (ie. $1 \mathrm{~g}$ of $\mathrm{Al}$ gave the same response as $12.5 \mathrm{~kg}$ of $\mathrm{P}$ ). 
The experiment consisted of a 2 minute irradiation, a 2 minute delay and 200 seconds of counting, using four rectangular $\mathrm{NaI}(\mathrm{Tl})$ detectors $(102 \times 102 \times 406$ $\mathrm{mm}$ ) arranged in an approximately $4 \pi$ geometry.

This study measured patients with aluminum-associated complications. The hand Al/Ca ratios varied from 0.02 to $0.76 \mathrm{mg} / \mathrm{g}$, with an average of 0.21 $\mathrm{mg} / \mathrm{g}$. The normal $\mathrm{A} / \mathrm{Ca}$ range is 0.02 to $0.04 \mathrm{mg} / \mathrm{g}$, from ICRP 23. No correlation was found between total body aluminum burden, from TBNAA, and either the skeletal aluminum or the AV Ca ratio for the hand. However, the increased serum aluminum levels due to the desferrioxamine mobilisation test were found to correlate to the hand $\mathrm{A} / \mathrm{Ca}$ ratios. This finding provides justification for the In Vivo method of neutron activation analysis of the hand.

A detection limit of $0.4 \mathrm{mg}$ of $\mathrm{Al}$, which is close to expected normal levels, was obtained for a hand dose of $20 \mathrm{mSv}$ in the Brookhaven study. The dose value is simply calculated from information on the beam. Since the hand represents $1.5 \%$ of the bone volume, and $1.5 \%$ of the skin, both organs having a weighting factor of 0.01 [23], the corresponding effective dose is $0.006 \mathrm{mSv}$. Assuming that the neutron beam contributes $1 \%$ of the hand dose to the body, the total effective whole body dose is approximately $0.21 \mathrm{mSv}$ [13].

The skeletal aluminum burden is determined from the product of the $\mathrm{Al}$ to Ca ratio from the hand measurement and the total quantity of calcium in the body. TBNAA or dual photon absorptiometry can provide the latter 
information. The results from the Brookhaven measurements show that the skeletal aluminum burden was $162 \mathrm{mg}$, from the hand activations of renal patients,and the mean total body aluminum burden was $1350 \mathrm{mg}$, from TBNAA, compared to 21 and $61 \mathrm{mg}$ for reference man (ICRP 23 [22]).

The third feasibility study was by Morgan et al. [34] for the Swansea In Vivo Analysis Research group. $\mathrm{A}^{252} \mathrm{Cf}$ source produced a neutron flux of $2 \times 10^{5}$ $\mathrm{n} / \mathrm{cm}^{2} / \mathrm{s}$, that was then filtered and moderated to obtain neutrons of epithermal and intermediate energy. The low resulting flux $\left(-10^{4} \mathrm{n} / \mathrm{cm}^{2} / \mathrm{s}\right)$ was compensated by using a 5-cycle activation. The irradiation time and the counting period, of one cycle, were both 240 seconds. Two opposed NaI(TI) detectors separated by a $70 \mathrm{~mm}$ air gap measured the spectrum of the irradiated hand. This process achieved $34 \%$ of the activity of the reactor method. The detection limit was 1.2 to $2.4 \mathrm{mg}$ of $\mathrm{Al}$, depending on the detection efficiency available and the background level achieved in Swansea. The Al to $P$ ratio was 600 counts to 1 , which compares to 12,500 to 1 from the Brookhaven study. However, the distinct advantage of this method is the portability of the neutron source which would permit large scale monitoring surveys.

Another approach, by Green and Chettle [18] at Birmingham University, used an accelerator-based system. A neutron beam was produced by bombarding a tritium target with protons $\left({ }^{3} \mathrm{H}\left({ }^{1} \mathrm{H}, \mathrm{n}\right)^{3} \mathrm{He}\right)$ in a Dynamitron 
accelerator. The irradiation cavity was constructed of a wax block moderating the proton beam, and graphite shielding surrounding the phantom position. The measurements consisted of exposing a sample to a 30 second neutron irradiation, and after a 30 second transfer time, four $\mathrm{NaI}(\mathrm{Tl})$ detectors (51 mm in diameter, $152 \mathrm{~mm}$ long) arranged in a $4 \pi$ geometry, counted the spectrum for 300 seconds. Samples of aluminum, phosphorous, and silicon were activated using a $2.4 \mathrm{MeV}$ proton beam. In a second series of measurements, phantoms of varying concentration of $\mathrm{AlCl}_{3} \cdot 6 \mathrm{H}_{2} \mathrm{O}$, to which $\mathrm{NaOH}$ and $\mathrm{NaCl}$ were added, were irradiated with $1.05 \mathrm{MeV}$ and 1.2 MeV protons. Since these NAA experiments were performed in hope of applying this In Vivo technique to patients, the dose delivered to the phantom must be monitored. Microdosimetric techniques were adopted for these purposes. The dose equivalent seemed to decrease as the proton energy decreased, but the neutron beam intensity decreased dramatically as the $1.0 \mathrm{MeV}$ reaction threshold was approached. Thus, a proton beam of $1.2 \mathrm{MeV}$, giving $150 \mathrm{keV}$ neutrons was chosen as the optimal energy. The resulting detection limit and sensitivity for the aluminum measurements was determined to be $2.0 \mathrm{mg}$ for a dose equivalent of $50 \mathrm{mSv}$, and 400 countg/mg/Sv, respectively. Due to the kinematics of the neutron production, the phosphorous interference was negligible as indicated by the Al to $\mathrm{P}$ ratio of 8500 to 1 .

A recent modification to this experimental design was conducted by 
Green et al. [17]. A large wax reflector was positioned behind the target to soften the neutron beam and the irradiation cavity volume was reduced. The counting system consisted of two $\mathrm{NaI}(\mathrm{Tl})$ detectors of dimensions $12.5 \times 12.5 \mathrm{~cm}$ and $15 \times 15 \mathrm{~cm}$, built into lead shielding. The Birmingham phantoms were compared to the Swansea group's phantoms. The latter are $400 \mathrm{ml}$ saline bags with physiologically realistic quantities of calcium, phosphorous, chlorine, and aluminum (varying from 0 to $30 \mathrm{mg}$ ). For an irradiation time of 30 seconds and a $1.2 \mathrm{MeV}$ proton beam, a hand dose of $13 \mathrm{mSv}$ was measured using microdosimetry. The minimum detection limit is 3.6 and $3.2 \mathrm{mg} \mathrm{Al}$ in the Swansea and the Birmingham phantoms, respectively. The sensitivities of the Brookhaven, Swansea and the present Birmingham systems (scaling for a neutron quality factor of 20 ) are thus $10,000,2450$, and $3700 \mathrm{Al}$ counts/mg/Sv, respectively. The superiority of the Brookhaven system may, in part, be attributable to a larger solid angle in the counting geometry. However, it is chiefly due to the use of a well thermalized reactor neutron beam, and hence a low absorbed dose per incident neutron.

\subsection{McMaster Study of Aluminum in Bone}

Based on the information acquired from the feasibility studies, the first step in developing a system for in vivo measurements of aluminum in bone is 
choosing a neutron source with the highest thermal energy component. Two neutron beam ports from the McMaster Nuclear Reactor are investigated as well as a $\mathrm{KN}$-accelerator-produced source, based on the ${ }^{7} \mathrm{Li}(\mathrm{p}, \mathrm{n})^{7} \mathrm{Be}$ reaction. A high thermal neutron flux is desired, which would minimize the phosphorous interference, while maximizing the activation per time ratio.

Once the most suitable neutron source is established, phantoms, physiologically representative of a reference-man hand, with varying amounts of added aluminum, can be irradiated. Analysis of the $\mathrm{Al}$ to $\mathrm{Ca}$ ratio as a function of added weight of aluminum gives a calibration curve and a minimum detection limit for the system. The dose associated with the irradiation procedure must also be measured and minimized, if possible. The goal is to investigate the feasibility of developing a facility where in vivo measurements of aluminum in bones can be routinely acquired. 


\section{Chapter II}

\section{Materials and Methods}

\subsection{Detection System}

The preliminary step in developing the neutron activation analysis method is creating phantoms that will represent a hand in a realistic fashion. Then, the most appropriate neutron source can be determined. However, before any steps can be undertaken, a detection system must be established. In this study, spectra are measured between the faces of two NaI(Tl) detectors, $200 \mathrm{~mm}$ in diameter $\times 50 \mathrm{~mm}$ thick, separated by $120 \mathrm{~mm}$ of air. The NaI(TI) detectors are chosen over pure Ge-type detectors based on their superior efficiency [28, p.231]. Furthermore, since the peaks of interest in the phantom spectra are significantly separated, the resolution of a pure Ge detector is not critical. The air gap between the detectors allows sufficient space for the resin phantoms to be easily inserted. An improvement would be to have flatter phantoms and to bring the detectors closer together in order to increase counting efficiency.

Each scintillation crystal has four photomultiplier tubes connected in 
parallel. The signal from each detector is transferred independently to two preamplifiers (CI model 1405), and then to two amplifiers (Harshaw Na-23, stabilized Amp/SCA). The signals are summed (Ortec model 433A) and sent to a pulse height analyzer (PHA) (Tracor Northern model 5103N) where the spectrum is displayed over 1024 channels. The amplifiers and the dual sum components are assembled in a NIM (Nuclear Instrument Module) bin (Canberra model 1400) arrangement. The power supply (Power Design Inc., model AEC-100), which is also a Nim component, sends a positive 600 VDC voltage to each photomultiplier tube anode separately. Once the spectrum has been accumulated in the PHA, the data are sent to a PC computer to be saved. (PC accumulation program assembled by $\mathrm{R}$. Fedorowicz).

The advantage of using two large opposed detectors is that a $4 \pi$ geometry is approached. Thus, the maximum numbers of $\gamma$-rays are counted. Furthermore, the geometry allows $\gamma$-rays, that have undergone Compton scattering in one detector, to contribute to the photopeak on the condition that the scattered $\gamma$-ray and the released electron are counted simultaneously in the two detectors. This maximizes the number of counts in the photopeak, improving the efficiency and thus the precision of the area measurements.

In order to reap the benefits of the geometry, the amplified signal from both detectors must be summed. The gain on both detectors is adjusted before a series of spectra is accumulated such that the gains are matched. This 
initial test consists of placing a ${ }^{60} \mathrm{Co}$ source between the detectors and monitoring the position of the $2.50 \mathrm{MeV}$ sum peak in each spectrum separately. The gains are varied until the peak position in both spectra is the same. To keep the gains similar from experiment to experiment, the $2.50 \mathrm{MeV}$ peak was chosen to be at a standard position of approximately channel 595, with a variance of a few $( \pm 2)$ channels. The reasoning for the standard position is to aid in the computerized analysis of the photopeaks.

The stability of the gains in each detector has been monitored through a series of measurements. Over a period of three hours, which is a typical duration of a series of activation measurements, the summed channel position of the $2.50 \mathrm{MeV}$ peak in the ${ }^{60} \mathrm{Co}$ spectrum shifts by less than $1 \%$. Both amplifiers show the same shift implying that it may be due to a fluctuation in the high voltage supply, or due to a change in detector response with varying temperature of the detection area. Thus, both amplifiers remain approximately gained matched, and their summed output will only vary by a few ( 3 to 5 ) channels, ie. less than $15 \%$ of the full width at half maximum. The result is that the resolution of the system should not vary throughout a series of measurement such that the shift will not hinder the analysis.

The $2.50 \mathrm{MeV}$ peak of the ${ }^{60} \mathrm{Co}$ spectrum is chosen as the gain calibration peak since it lies in the energy range of interest. Furthermore, a high energy peak will demonstrate more clearly the channel position changes 
due to gain variations.

Stabilized amplifiers (SCA) were used in an attempt to improve the gain stability in the spectrum. The SCA functions by tracking the position of a peak, chosen by selecting an energy value and window size, and adjusting the gain in order to prevent the position from varying over a value, inherent to the instrument (approximately $10 \%$ ). In the phantom spectrum, the only activated element that is sufficiently long lived to permit tracking is calcium. However, tests have shown that even this element decays too rapidly to allow a long enough time to set the tracking on the peak position. Furthermore, the physiological realistic concentration of calcium in the phantoms does not give sufficient counts in the peak to allow proper tracking. Consequently, the amplifiers, without the benefit of tracking, are used throughout the experiments.

\subsection{Analysis}

The original design for the analysis program was to use a "deconvolution -type" method. This technique consists of first accumulating spectra of each individual element that will be present in the phantom spectrum, and then, deconvolving these spectra from the phantom spectrum. The multiplication factor permitting the appropriate "subtraction" of each element gives a 
measure of the quantity of the element present in the mixture. The problem with this analysis method is that all the spectra must have the same gain. Gain shifts of a few channels would require rebinning each spectrum to match the "standard" gain. Thus, the SCAs were investigated for additional gain stability, but the difficulties associated with their use counteracted any benefits. For most experiments, it was shown not to be possible to maintain gain stability to the levels demanded by the analysis program, ie. variations less than a couple of channels. The result is that a deconvolution technique of analysis is not practically feasible and this method was abandoned.

A simpler method of analysis is to fit each photopeak in the phantom spectrum to a Gaussian curve, and to calculate the net area under the curve, with the background subtracted. The analysis program that calculated the results cited in this report used this technique [27] and it is based on the Marquardt method of non-linear fitting [3].

Initially, the program is used to analyze the photopeaks of ${ }^{24} \mathrm{Na}(1.37$ and $2.75 \mathrm{MeV}),{ }^{38} \mathrm{Cl}(1.64$ and $2.17 \mathrm{MeV})$, and ${ }^{49} \mathrm{Ca}(3.08 \mathrm{MeV})$ in the spectrum. According to theory [28], the square of a Gaussian width is directly proportional to the peak energy. This relationship can be described by:

$$
\sigma^{2}=k_{1}+k_{2} E
$$


where $\sigma=$ standard deviation of Gaussian curve

$\mathbf{k}_{1}=$ broadening factor due to electronic components

$k_{2}=$ factor describing inherent statistical variations in collected photoelectrons

$E=$ peak energy

Thus, there is a broadening of the peaks with increasing energy.

By fitting the spectra, the squares of the standard deviations can be related as functions of the energies of each photopeak (see Fig. 2.1). From the information derived from this straight line, the fitting program can search a given energy range for a peak with a specific standard deviation. However, as seen in Figure 2.2, the aluminum photopeak lies on the tail end of the chlorine peak. Thus, to determine the area under the aluminum peak, a pair of Gaussians must be fitted to the ${ }^{38} \mathrm{Cl}$ and ${ }^{28} \mathrm{Al}$ lines. Since gain shifts may cause spectral broadening, a fixed difference in standard deviation for the two peaks is set, instead of fixed individual values. Therefore, the program can compensate for variations in individual peak channel number and widths, due to gain instabilities. The calcium peak is fitted separately to a Gaussian of fixed standard deviation.

To obtain the net area under a peak, the background must be subtracted from the Gaussian area. The background area seems independent of the model used. Thus, a simple straight line fit is chosen. 


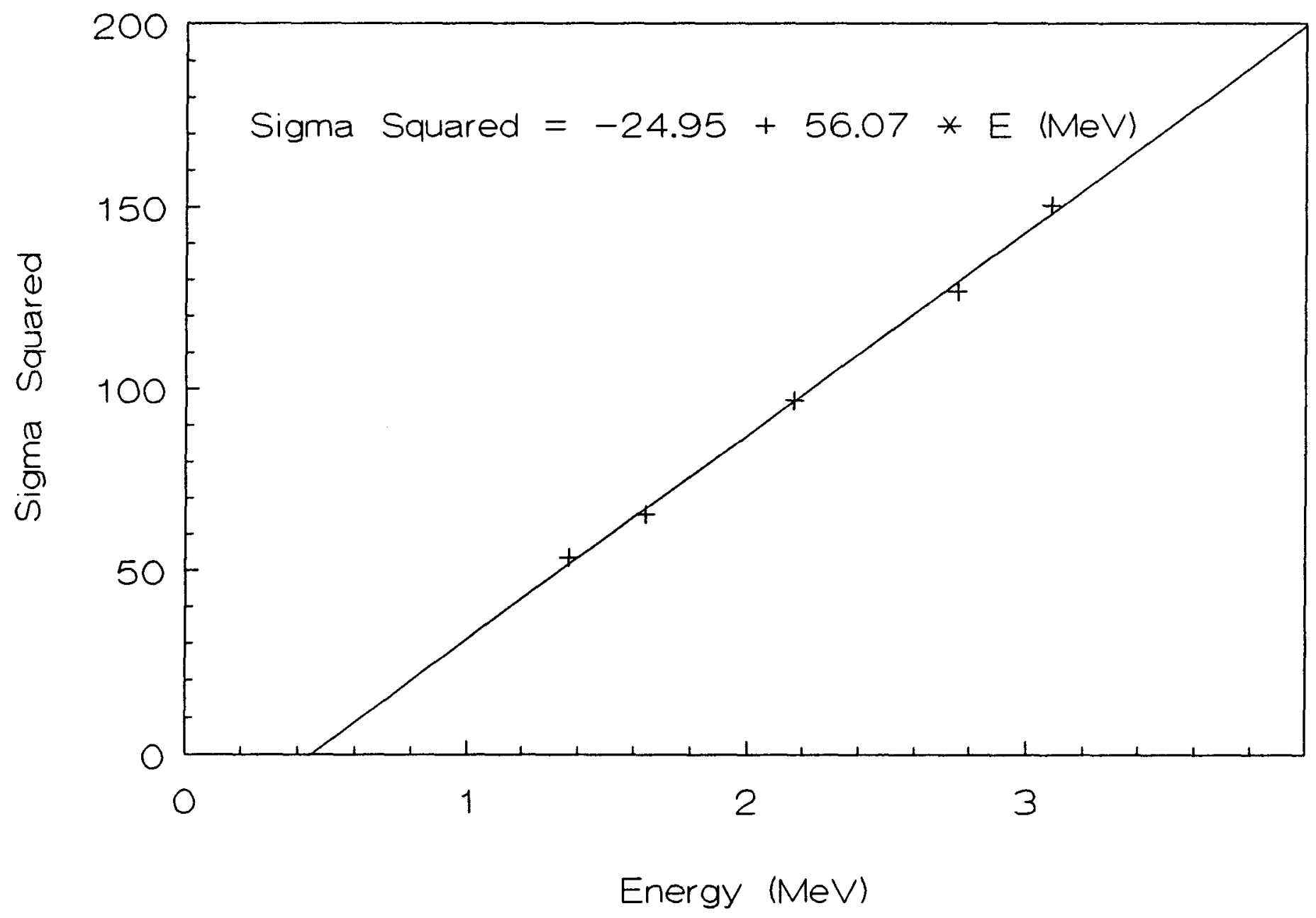

Figure 2.1: Relation Between Peak Width Squared and $\gamma$-Ray Energy. 


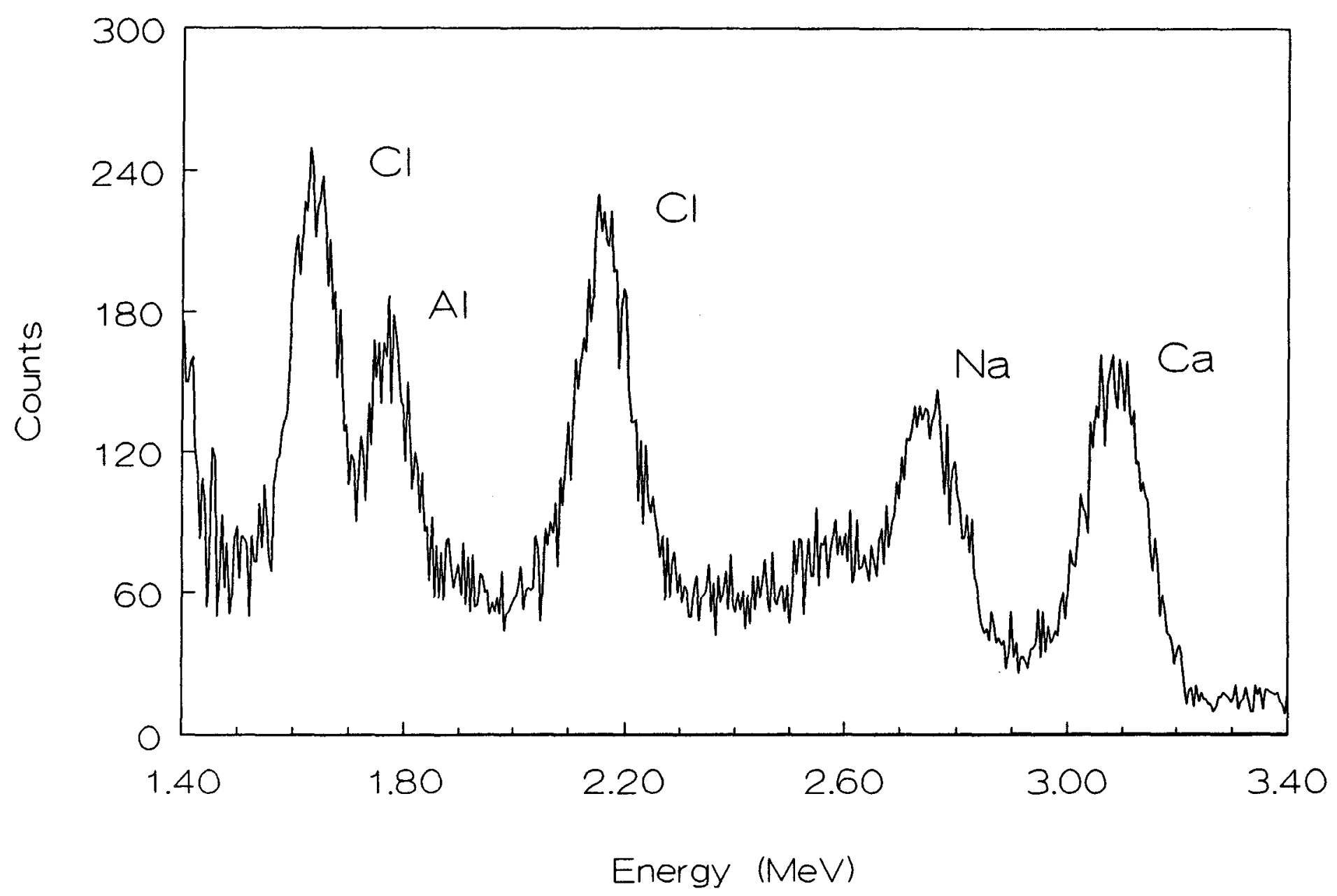

Figure 2.2: Spectrum of a Resin Hand Phantom ( $0.5 \mathrm{mg}$ of added $\mathrm{Al}$ ). 
Data are interpreted in the form of a calibration curve. The ratios of the aluminum to calcium net areas are plotted as functions of the added weight of aluminum in the phantoms. The phantoms have physiologically realistic concentrations of the elements that can be activated in the hand. These elements include $\mathrm{Al}, \mathrm{Ca}, \mathrm{Cl}, \mathrm{Na}$, and $\mathrm{P}$. Other elements commonly present in $\mathbf{a}$ hand are considered "inert" in this study. The reason is that the thermal neutron activation of some elements, like hydrogen or nitrogen, will only emit prompt $\gamma$-rays, which are not detected in this system. Hydrogen will also undergo elastic collision with the thermal neutrons. Finally, common elements like oxygen and carbon have low neutron absorption cross sections, and are thus undetectable in these experiments.

A minimum detection limit (MDL) is calculated from the fit of the calibration line. It is defined as:

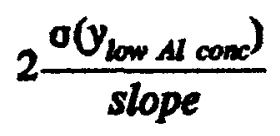

where $\sigma\left(y_{\text {low Al cond }}\right)=$ uncertainty in a low aluminum concentration point. A combination of MDL and dose delivered to the phantom will characterize the experiment's sensitivity to aluminum. 


\subsection{Phantoms}

The first generation of phantoms are varying weights of powdered chemicals enclosed in polyethylene-like (nalgene) bottles. The chemicals are compounds containing elements present in the hand that can be activated by the neutron beam, and other elements "inert" to the radiation. These compounds are $\mathrm{Ca}$ (metal), $\mathrm{LiCl}, \mathrm{SiO}_{2}, \mathrm{NH}_{4} \mathrm{H}_{2} \mathrm{PO}_{4}, \mathrm{NaNO}_{2}$ (or $\mathrm{Na}_{2} \mathrm{CO}_{3}$ ) and $\mathrm{Al}\left(\mathrm{NO}_{3}\right)_{3} \cdot 9 \mathrm{H}_{2} \mathrm{O}$. This series of phantoms was used solely for the preliminary experiments.

Comparing the spectrum of an empty nalgene bottle to that of an aluminum-filled bottle, it is discovered that the nalgene containers have an aluminum impurity of approximately $8 \mathrm{mg}$. The level of contamination is calculated by determining the Gaussian area of the aluminum peak in the empty and aluminum filled bottle spectra, and then multiplying the ratio of the nalgene aluminum to the added aluminum areas by the added aluminum weight. However, the calculation is somewhat inaccurate since the geometry of the aluminum distribution in the plastic is different from that of the powdered aluminum compound. Furthermore, the aluminum powder may cause some attenuation of the neutron beam as well as of the escaping $\gamma$-rays such that the experimental conditions could be different from the irradiation of the empty nalgene bottle. Thus, the estimate of aluminum impurity is 
presented only as an order of magnitude approximation. Since a typical hand should contain only about $0.3 \mathrm{mg}$ of Al (ICRP 23 [22]), this impurity renders the first generation phantoms impractical for this study. The finding of aluminum contamination in polyethylene bottles agrees with the Landsberger and Arendt study [30]. In their paper, the aluminum impurity varied from one vial to another such that it would be impossible to standardize the value.

The idea of encasing the powdered compounds in a matrix, instead of enclosing them in a container governed the creation of the second generation of phantoms. Cylindrical bone phantoms were constructed to resemble the physiological composition of a typical hand, according to ICRP 23 reference man. The phantom shape, $76 \mathrm{~mm}$ in diameter $\times 90 \mathrm{~mm}$ in height, would reproduce the geometry of a clenched fist. An $11 \mathrm{~cm}$ section of a PVC tube ( $3^{\prime \prime}$ internal diameter) was used as a mold, with a plastic cap to close one end. The molds were first cleaned with acetone. It was noted that this chemical seemed to melt a fine layer of the PVC tube. Thus, the mold was allowed to dry before being used. Polyester resin was used as a substrate, to which fixed amounts of bone ash, ie. $\mathrm{Ca}_{10}\left(\mathrm{PO}_{4}\right)_{6}(\mathrm{OH})_{2}(37.53 \mathrm{~g}), \mathrm{NaCl}(2.35 \mathrm{~g}), \mathrm{Na}_{2} \mathrm{CO}_{3}(1.33$ g), and varying amounts of $\mathrm{Al}\left(\mathrm{NO}_{3}\right)_{3} \cdot 9 \mathrm{H}_{2} \mathrm{O}$ (corresponding to $0,0.5,2,5,20$ and $50 \mathrm{mg}$ of $\mathrm{Al}$ ) were introduced. The resin and chemical mixture was then set using a methyl ethyl ketone peroxide catalyst (Quickset extra), mixed in an approximate ratio of 1 part catalyst to 100 parts resin, ie. about 400 to $500 \mathrm{ml}$ 
of resin was used such that approximately 4 to $5 \mathrm{ml}$ of catalyst was needed. The mixture was stirred with a glass rod for approximately 20 minutes (varying according to the quantity of catalyst added) in order to evenly distribute the chemicals throughout the phantom. After this time period, the resin would begin to harden quickly. This reaction caused the phantom to become hot to the touch. The mold was thus put in a bath of wet sand to draw the heat away. This temperature increase caused no structural damage to the mold, and very little to the plastic cap. It is assumed that negligible impurities would come from contact of the phantom with the mold.

After letting the phantom harden and cool, over a period of a night, the plastic cap was removed from the mold, and the phantom was pushed out and allowed to dry further.

Phantoms consisting of only resin, and resin plus bone ash, were also constructed to investigate the presence of aluminum impurities in the matrix itself, and in the bone ash. This substance, contrary to the other chemicals used, is not of a high purity. It is simply the type of bone ash used for pottery.

\subsection{Experimental Design}

The irradiation experiments consist of exposing a phantom to a beam of neutrons for 3 minutes, and counting the spectrum for 5 minutes, between 
the two $\mathrm{NaI}(\mathrm{Tl})$ detectors.

The irradiation time of 3 minutes was chosen from comparison with the Brookhaven group [13], that also used a nuclear reactor as a neutron source. Their study used an irradiation time of 2 minutes for a thermaVepithermal neutron flux of $1.36 \times 10^{7} \mathrm{~m} / \mathrm{cm}^{2} / \mathrm{s}$. The beam port used for most of the experiments has a total neutron flux of $\sim 4 \times 10^{7} \mathrm{n} / \mathrm{cm}^{2} / \mathrm{s}$. Since the thermal neutron component would only be a fraction of this flux, a slightly higher irradiation time was chosen.

The counting time was determined on the basis of the half-life of ${ }^{28} \mathrm{Al}$ (2.3 minutes). In 5 minutes, the measurement of the aluminum signal would be maximized in comparison to the accumulation of background counts. Originally, the 5 minutes were live time of the PHA. For the later experiments, it was changed to clock time. However, since no dead time was noted, this difference should not be significant.

In this study, three types of neutron sources were compared: two neutron beam ports from the McMaster Nuclear Reactor and neutrons generated by a $\mathrm{KN}$-accelerator by the ${ }^{7} \mathrm{Li}(\mathrm{p}, \mathrm{n})^{7} \mathrm{Be}$ reaction. A neutron source emitting a high flux, low energy (preferably thermal) beam is sought. The ease of access to the beam must also be considered for future patient measurements (see Sect. 3.1 for further details).

The first beam port used, designated "Beam Port 2", had a "walk-in" 
type access. To enter, a sliding door is pushed open, and the sample to be irradiated is positioned a few centimetres from the beam port exit, with the use of a table. The beam is opened and shut by a switch outside the door.

"Beam Port 4" is the second neutron source examined. Samples are positioned on a stand at approximately $140 \mathrm{~cm}$ from the beam exit (ie. in front of the beam stop). Access to the beam port is from the top. Thus the stand must be lowered into the cave. Its position is marked down in order to achieve reproducibility of sample positioning. The cave remains open during the experiments. Since the neutron beam is well collimated and is at mid-height of the cave, a very low dose of $25 \mu \mathrm{Sv} / \mathrm{hr}$ is measured at the top, using a portable neutron monitor (Tracerlab NP-1 [42], see Chap. 5)

When nalgene bottles are irradiated in beam port 4, the stand is mounted with a pipe, acting as a guide shoot, which is open at the end to let the beam enter. The guide tube permits lowering and removing of the bottle from the floor above the beam port level. The detection room and the beam shutter control are both on this upper floor. For the resin phantoms, the guide tube must be removed since its bore is too small to permit passage of the samples. The phantoms are positioned manually on the stand. In a similar fashion as the bottles, they are removed from the upper floor, with the use of string tied around the phantom body, and a rod to help in leverage. The transfer time of the phantoms, from the irradiation area to the detectors, was 
approximately 50 seconds for both beam ports.

The third neutron source uses the $\mathrm{KN}$-accelerator where the neutrons produced by the ${ }^{7} \mathrm{Li}(p, n)^{7} \mathrm{Be}$ reaction are moderated by a wax box surrounding the sample (see Chap.3). After the irradiation, the sample is removed from the accelerator room by crossing through two interlock doors (to enter and to exit). The phantom must then be brought from the accelerator building to the reactor, where the detection area is situated, by first crossing through a double door air lock. Due to these difficulties, the transfer time is increased to 2 minutes for the experiments using the $\mathrm{KN}$-accelerator as a neutron source. 
Chapter III

\section{Comparison of Neutron Sources}

\subsection{Neutron Sources}

A preliminary study was undertaken to assess the most appropriate neutron source available for in vivo neutron activation analysis. Two neutron beam ports form the McMaster Nuclear Reactor (see Fig.3.1) were investigated as well as a KN-accelerator-produced source, based on the ${ }^{7} \mathrm{Li}(\mathrm{p}, \mathrm{n})^{7} \mathrm{Be}$ reaction.

Ideally, a high thermal neutron flux at the bone surface is required. In patient studies, a hand, or a foot, will be exposed to the neutron beam. Since either of these extremities has a very thin tissue layer protecting the bone, a thermal beam should provide sufficient aluminum activations considering that the thermal neutrons survival length in tissue is 2 to $3 \mathrm{~cm}$. However, an epithermal beam would be preferred since it could provide the leeway for possible thermalization of the beam before the bone is reached, or in the bone itself. Epithermal neutrons could reach aluminum deeper in the bone than a pure thermal beam. A high flux will maximize the aluminum activations, while a low energy beam will minimize the damage due to the radiation. For fast neutrons, the radiation dose delivered to the hand, say, is primarily due 


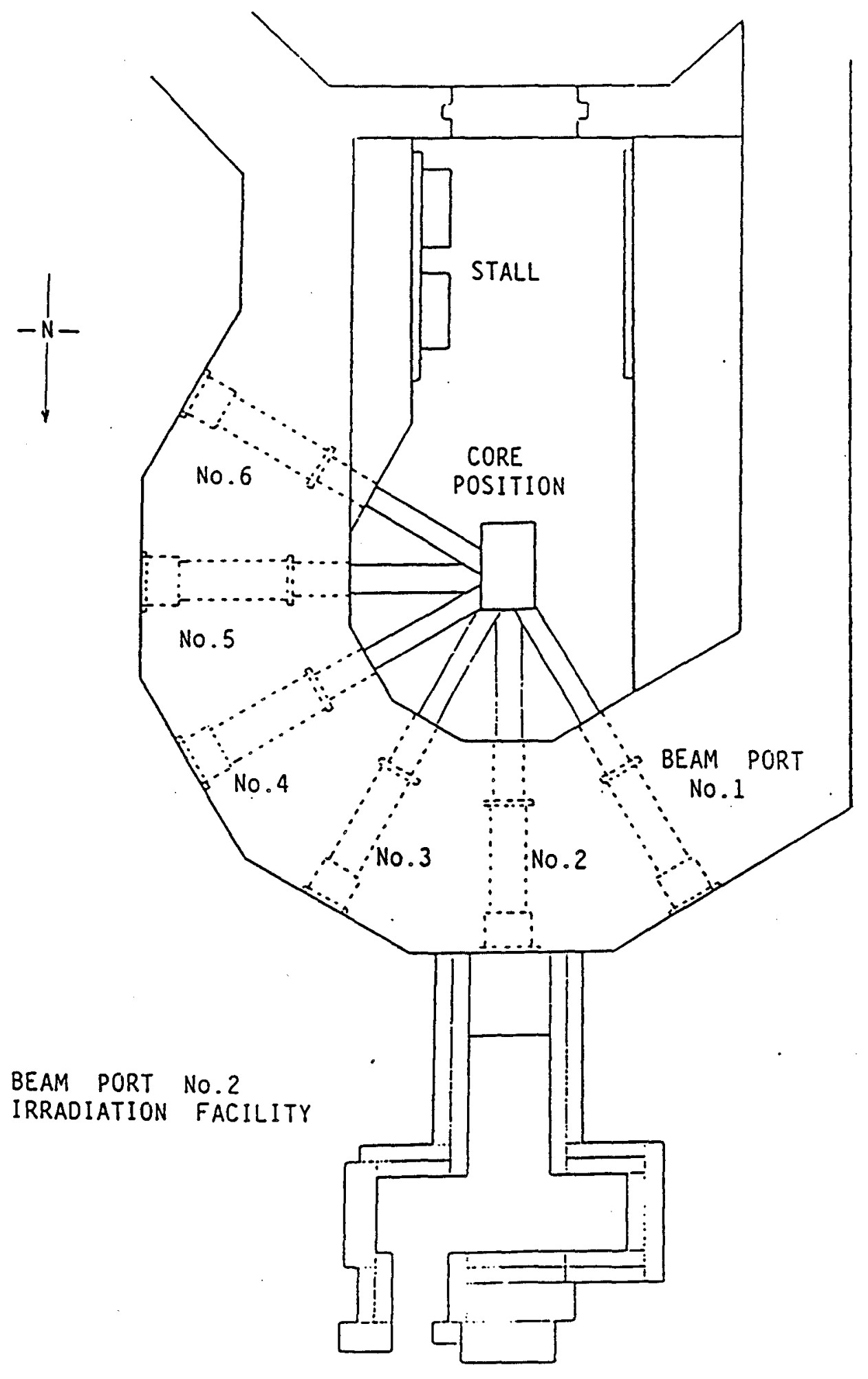

Figure 3.1: Schematic of the McMaster Nuclear Reactor Beam Ports. 
to elastic recoil of the neutrons on hydrogen. The protons acquiring this energy can cause large amounts of radiation damage. According to ICRP 60 [24], the equivalent dose, $H$, is defined as the product of the absorbed dose, $D$, and the radiation weighting factor, $w_{R}$, ie. $H=D \times w_{R}$. The damage due to fast neutrons can be inferred from the plot of the radiation weighting factors as functions of incident neutron energy (see Fig. 3.2). The radiation weighting factor for a specified type and energy of radiation is representative of values of the relative biological effectiveness (RBE) of the radiation in inducing stochastic effects at low doses. RBE of a radiation is defined in comparison to another as the inverse ratio of the absorbed doses producing the same degree of a defined biological end-point.

Thermal neutrons, on the other hand, react in tissue by the ${ }^{14} N(n, p){ }^{14} C$ and the ${ }^{1} \mathrm{H}(\mathrm{n}, \gamma)^{2} \mathrm{H}$ reactions. In this case, the production of protons from the nitrogen activation is the predominant contributor to the thermal dose since, in a hand, the $2.2 \mathrm{MeV} \gamma$-rays from the reactions with hydrogen will escape from the thin layer of tissue. Since this production is indirect and thus controlled by the reaction cross section of $1.8 \mathrm{barn}$, the thermal dose is less significant than that due to higher energy neutrons. Furthermore, there is considerably less nitrogen in the body than hydrogen: in a $75 \mathrm{~kg}$ reference man, there is $7000 \mathrm{~g}$ of $\mathrm{H}$ whereas only $1800 \mathrm{~g}$ of $\mathrm{N}$ [22]. In other words, the hydrogen number density is 50 to 60 times greater than that of nitrogen. The 


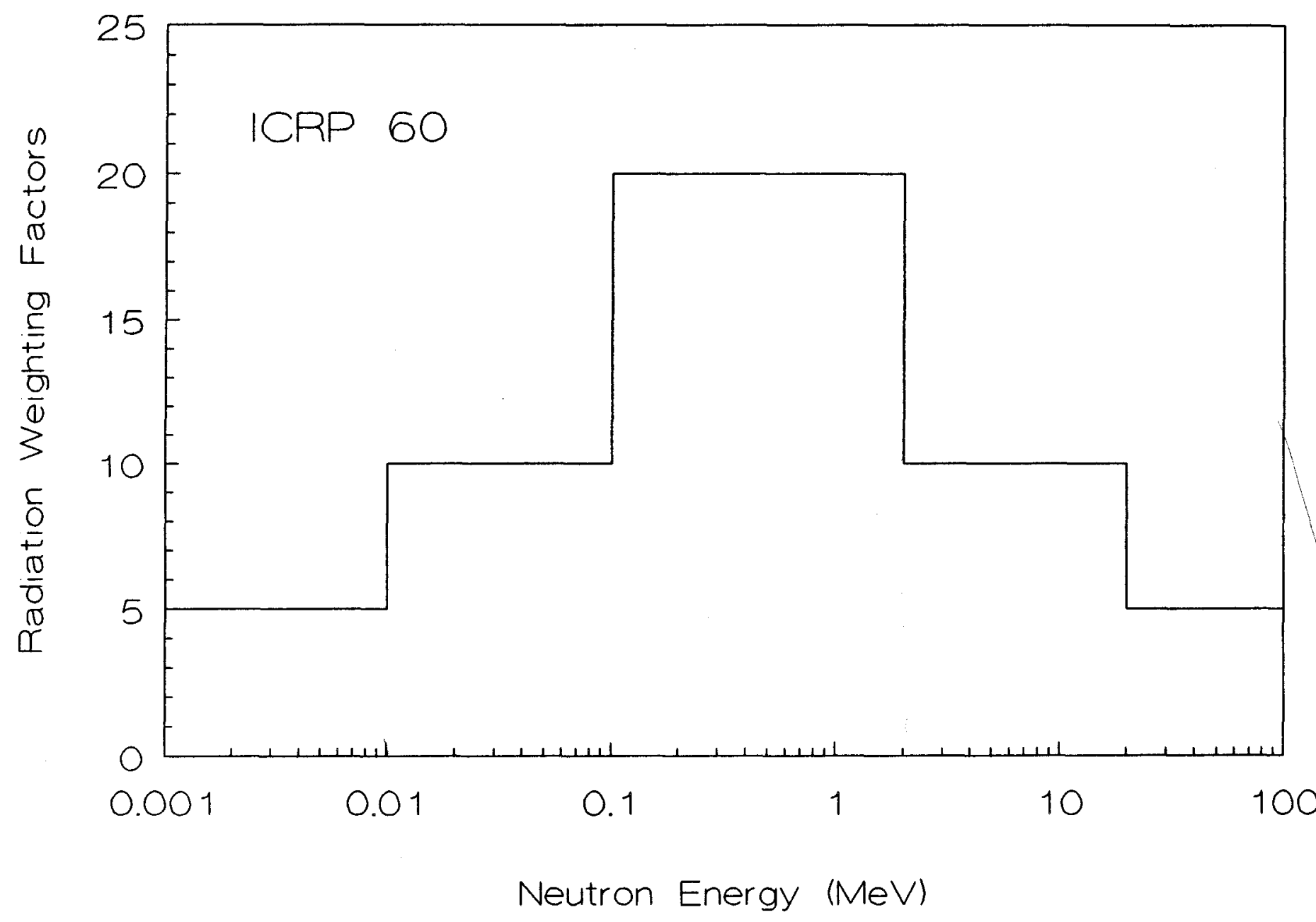


$\gamma$-ray released in the hydrogen activation does not in comparison cause large radiation damage since its radiation weighting factor is only 1 . In conclusion, from comparison of the radiation weighting factors, thermal neutrons will cause less damage in tissue than neutrons with energies from $10 \mathrm{keV}$ to 20 $\mathrm{MeV}$.

The elimination, or at least the reduction, of the interferences due to the ${ }^{31} \mathrm{P}(\mathrm{n}, \alpha){ }^{28} \mathrm{Al}$ and ${ }^{28} \mathrm{Si}(\mathrm{n}, \mathrm{p})^{28} \mathrm{Al}$ reactions would also be achieved with a thermal beam. The thresholds for the production of ${ }^{28} \mathrm{Al}$ from phosphorous and silicon are 1.95 and $4.0 \mathrm{MeV}$ respectively, whereas ${ }^{27} \mathrm{Al}(\mathrm{n}, \gamma)^{28} \mathrm{Al}$ is a thermal neutron reaction.

"Beam Port 2" was the first reactor based source examined. It is primarily used for neutron radiography. The beam itself has a degraded fission spectrum but no specific neutron thermalization filtration. The total neutron flux is estimated as approximately $10^{6} \mathrm{n} / \mathrm{cm}^{2} / \mathrm{s}$, for a beam port aperture of $20 \mathrm{~cm} \times 20 \mathrm{~cm}$. In comparison, the other reactor source, designated "Beam Port 4", has a filter, whose main elements are silicon and a sapphire crystal, which is designated specifically to remove fast neutrons (see Fig. 3.3). Furthermore, its total neutron flux, $\sim 4 \times 10^{7} \mathrm{n} / \mathrm{cm}^{2} / \mathrm{s}$, is greater than that of beam port 2 . The aperture of beam port 4 however is only about $2.5 \mathrm{~cm} \times 5$ cm. In both reactor beam ports, the samples to be irradiated are placed directly in the beam path. The main disadvantage of beam port 4 , however is 


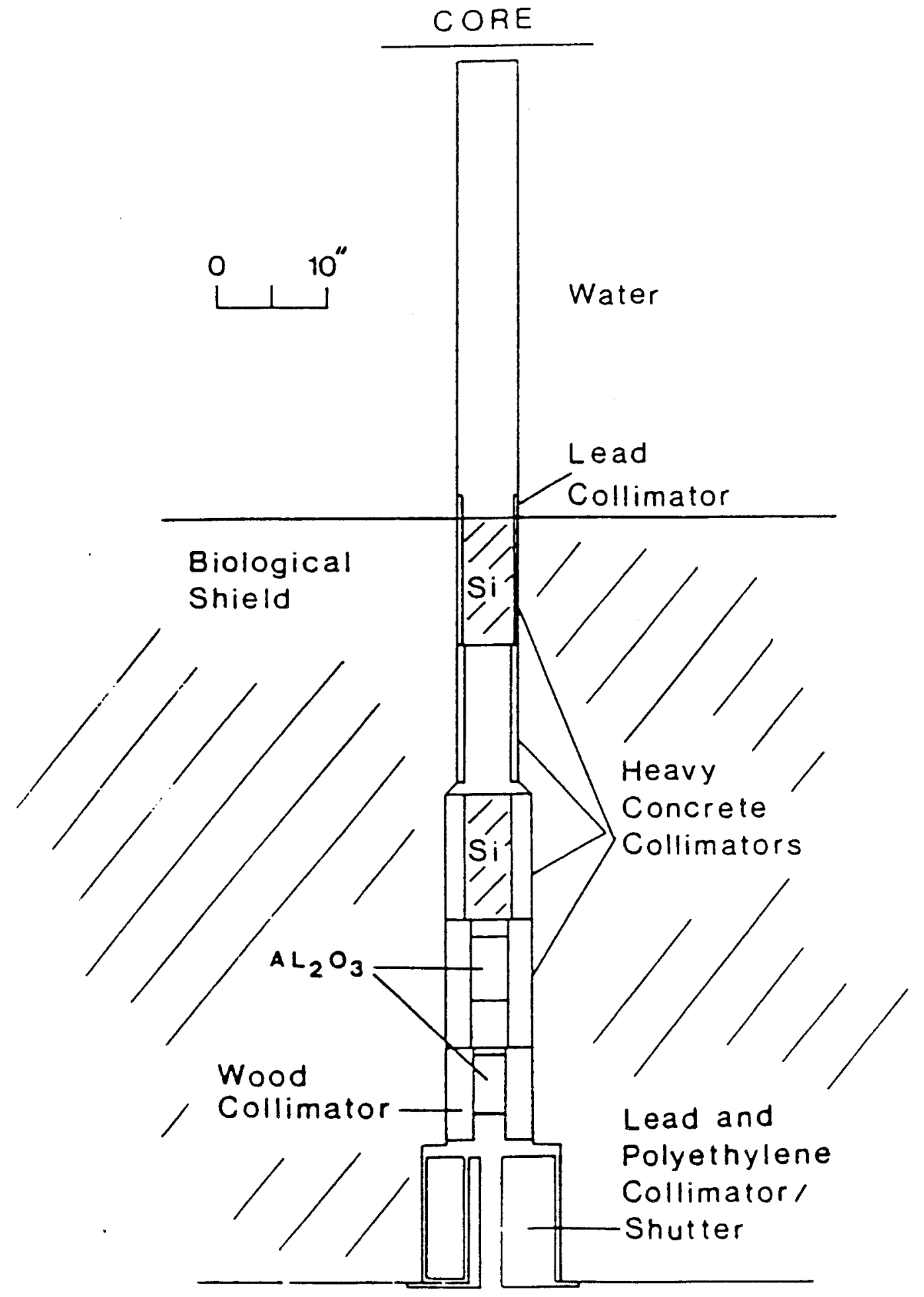

Figure 3.3: Beam Port 4 Diagram. 
$\mathrm{p}+{ }^{7} \mathrm{Li} \longrightarrow \mathrm{n}+{ }^{7} \mathrm{Be}$

$\mathrm{E}_{\mathrm{p}}=(2.00+/-0.02) \mathrm{MeV}$

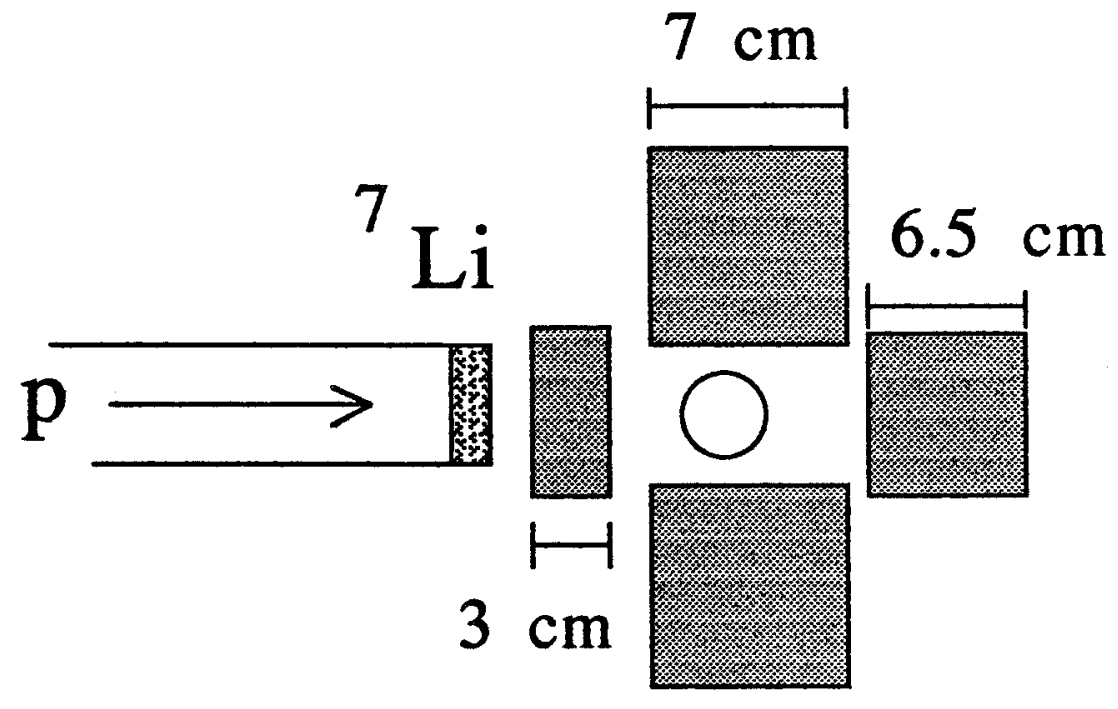

$=$ paraffin wax

$\bigcirc=$ nalgene bottle

Figure 3.4: KN-Accelerator Diagram. 
its difficult access (see Sect. 2.4). For eventual patient measurements, where a hand or a foot would be exposed to the beam, the ease of patient positioning would become an important point.

Lastly, in the $\mathrm{KN}$-accelerator, a ${ }^{7} \mathrm{Li}$ target was bombarded with protons to create the ${ }^{7} \mathrm{Li}(\mathrm{p}, \mathrm{n})^{7} \mathrm{Be}$ reaction (see Fig.3.4). The proton energy was chosen to be approximately the threshold energy of the reaction such that the produced neutrons will have the minimum energy possible.

The $Q$ value for this endothermic reaction is $1.6943 \mathrm{MeV}$. In the laboratory frame of reference, the threshold kinetic energy, $K_{t h}$, must be slightly greater than the $Q$ value in order for the outgoing particles to allow momentum conservation. From the conservation of energy principle, the threshold energy in a nuclear collision is [43]:

$$
K_{t h}=-\frac{\left.Q^{(\text {rest mass of all particles entering }}+\text { leaving the reaction }\right)}{2(\text { rest mass of target particle })}
$$

For low-energy reactions, the $\mathrm{Q}$ value is of the order of a few $\mathrm{MeV}$ and is thus much lower than the rest energies of the collision components. From the definition of the $Q$ value,

$$
\frac{Q}{c^{2}}=\left(\sum \text { rest mass before }\right)-\left(\sum \text { rest mass after }\right)
$$

this would imply that the rest masses before and after the reaction are 
comparable. Consequently, for the reaction of interest, equation [3.1] can be approximated by:

$$
K_{t t}=-Q\left(\frac{m_{p}+M_{u}}{M_{L i}}\right)
$$

To reach the resonance for the production of neutrons by these means, approximately $30 \mathrm{keV}$ must added to the $Q$ value. Thus, the proton energy necessary to achieve the resonance is approximately $1.97 \mathrm{MeV}$. The protons bombarded the lithium target with an energy of 1.99 to $2.00 \mathrm{MeV}$. The uncertainty in the proton energy setting ( $20 \mathrm{keV}$ ), for the accelerator, was added to the threshold energy in order to guarantee that the reaction will occur. The current applied to the filament to produce the protons was approximately $45 \mu \mathrm{A}$.

Using classical mechanics, and assuming the neutrons are emitted along the beam path, the energy of the neutrons can be calculated. The velocity of the neutrons is obtained from the sum of the centre of mass velocity and the velocity of the neutrons relative to the centre of mass. Since the energy, K, put in the reaction is more than the threshold value, equation 3.3 becomes:

$$
K=\frac{m_{P}+M_{u}}{M_{u}}\left(Q+E_{\text {ovoll } C M}\right)
$$

where $\mathrm{E}_{\mathrm{aval}} \mathrm{CM}=$ energy available in the centre of mass 
The neutron therefore takes, in the centre of mass:

$$
E_{n C M}=\frac{M_{B e}}{M_{B e}+m_{n}} E_{\text {avall } C M}
$$

The centre of mass itself has:

$$
E_{C M}=\frac{m_{n}}{m_{n}+M_{B e}} K
$$

Thus, the energy of the neutrons, released in the reaction, is calculated to be approximately $152 \mathrm{keV}$. Consequently, from these kinematics, the neutrons produced should not have sufficient energy to be capable of activating the interference reactions of phosphorous or silicon.

To thermalize the neutrons, two blocks of paraffin wax, totalling $3 \mathrm{~cm}$ in width, are placed approximately $5 \mathrm{~cm}$ in front of the ${ }^{7} \mathrm{Li}$ target (see Fig. 3.4). A wax box is then created by combining the front moderating blocks with wax blocks $6.5 \mathrm{~cm}$ in width at the back, and $7.5 \mathrm{~cm}$ in width on both sides. The samples are irradiated in this wax castle, designed to scatter the neutrons back into the irradiation area, thus maximizing the aluminum activations.

The neutron flux during the irradiations, at a position approximating the phantom position, corresponded to a dose of $1 \mathrm{mSv}$ per hour. For a 3 minute irradiation of a hand, the corresponding hand dose equivalent is $50 \mu \mathrm{Sv}$. A second resonance could have been achieved with $2.10 \mathrm{MeV}$ protons. This energy would have produced a much larger neutron flux, but also a higher 
mean neutron energy. Faster neutrons will increase the dose due to the irradiation, as explained earlier in this section. Since a physiologically realistic weight of calcium, for a hand, was easily detected using $2.00 \mathrm{MeV}$ protons, the neutron flux produced is considered sufficient. Calcium is used as a guide of the relative thermal neutron flux since it is a difficult element to activate. ${ }^{48} \mathrm{Ca}$ is the only suitable isotope that undergoes an activation reaction $\left({ }^{48} \mathrm{Ca}(\mathrm{n}, \gamma){ }^{49} \mathrm{Ca}\right)$ that is measurable by $\gamma$-ray emission external to the body, and it is present in only $0.18 \%$ of natural calcium. Thus, $27 \mathrm{mg}{ }^{48} \mathrm{Ca}$ is present in $15 \mathrm{~g}$ natural $\mathrm{Ca}$ for a reference man hand [22].

\subsection{Comparison of Thermal Neutron Output}

Powdered samples of $\mathrm{Al}\left(\mathrm{NO}_{3}\right)_{3} \cdot 9 \mathrm{H}_{2} \mathrm{O}, \mathrm{NH}_{4} \mathrm{H}_{2} \mathrm{PO}_{4}$, and $\mathrm{SiO}_{2}$, contained in nalgene bottles, were irradiated for 3 minutes in each of the three neutron sources in order to measure their relative thermal neutron outputs. For the accelerator experiments, calcium was added to the phosphorous phantom to verify that the thermal neutron flux would be sufficient for the human hand measurements (see Sect. 3.1).

Comparing the spectra from each source separately (see Figures 3.5, 3.6, and 3.7), the fast ( $>1.95 \mathrm{MeV})$ to thermal neutron flux ratio can be obtained, by weighting a ratio of the net areas under the phosphorous and 


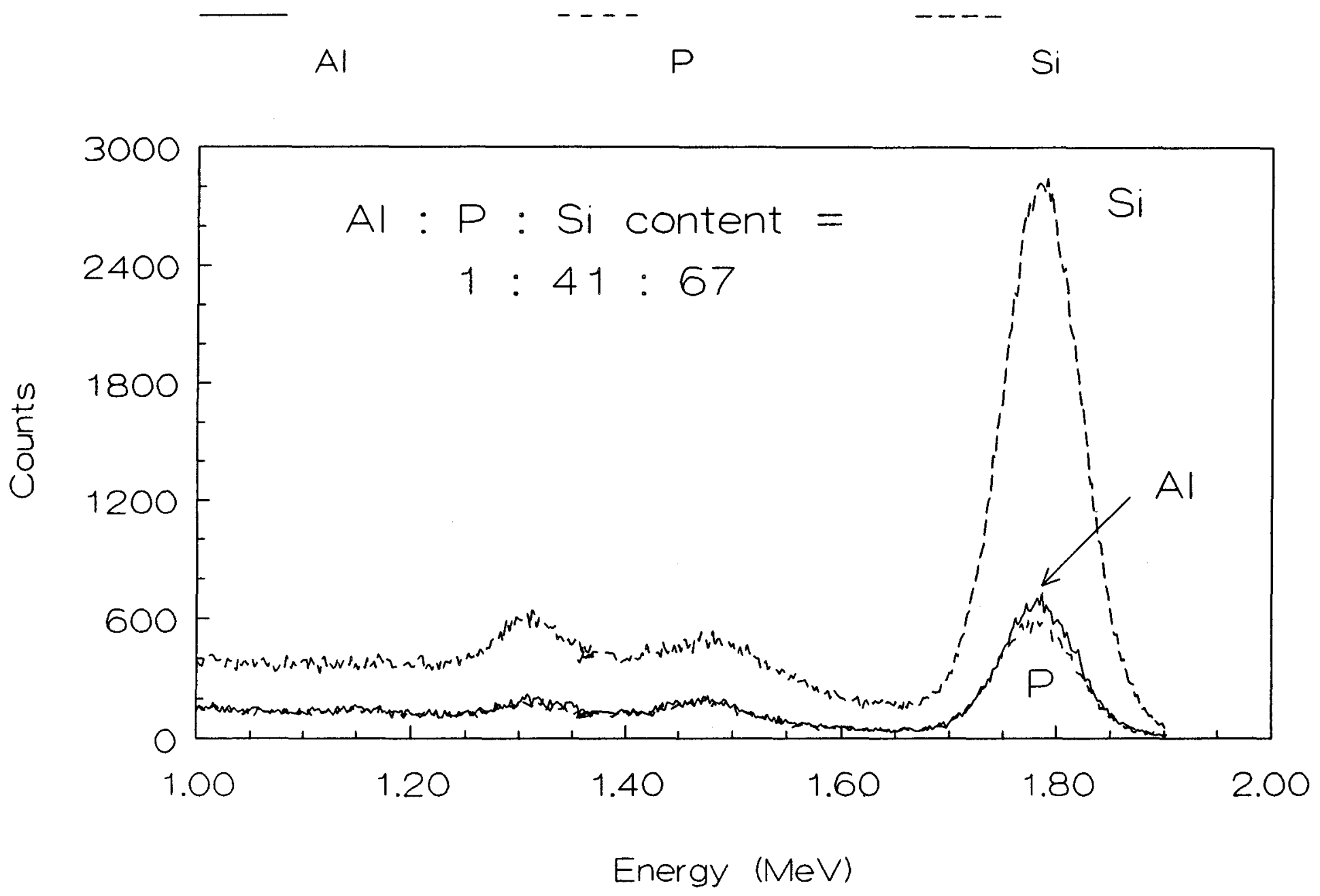

Figure 3.5: Comparison of Neutron Sources: Beam Port 2. 


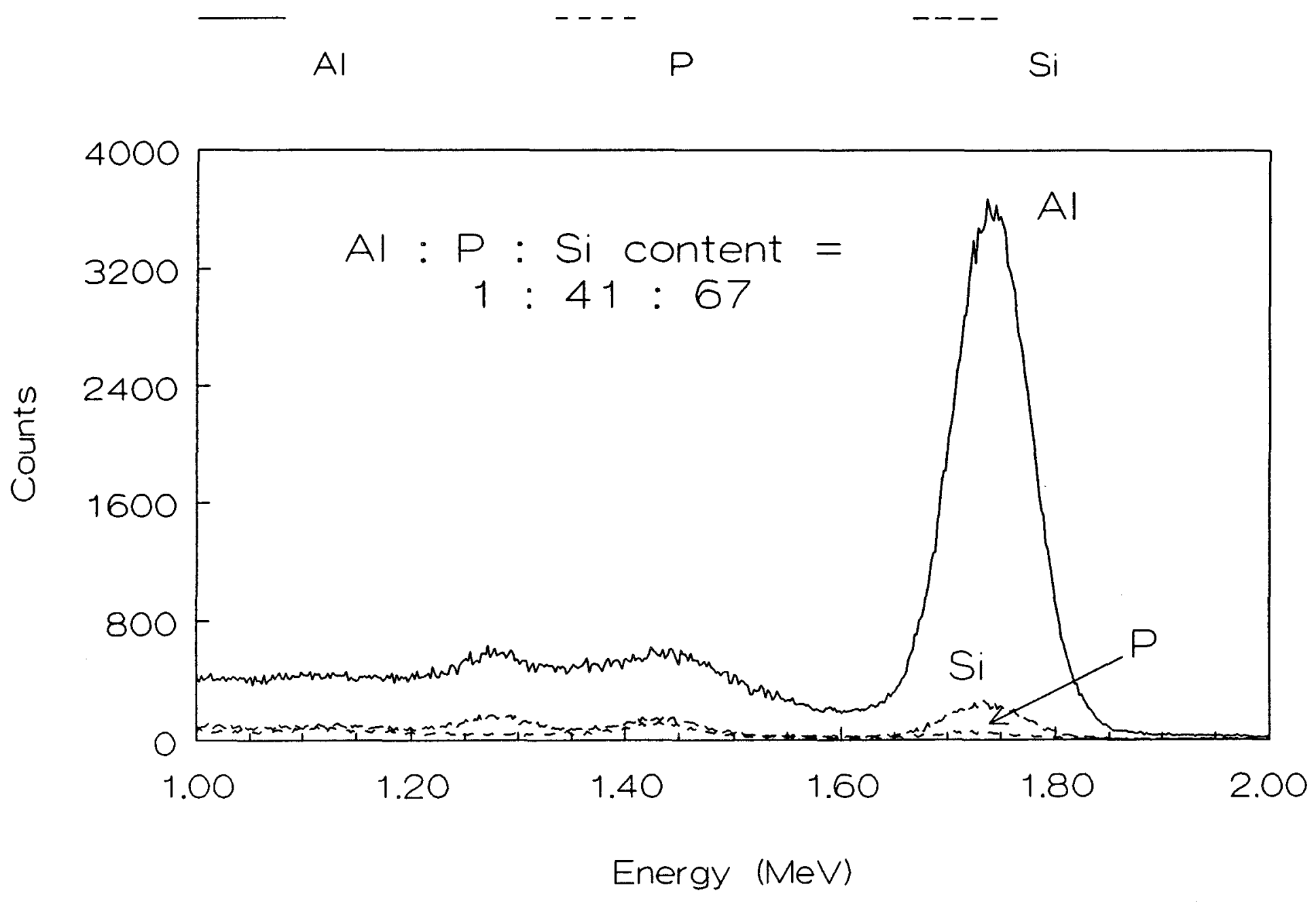

Figure 3.6: Comparison of Neutron Sources: Beam Port 4. 


$$
\text { Al : Ca }
$$

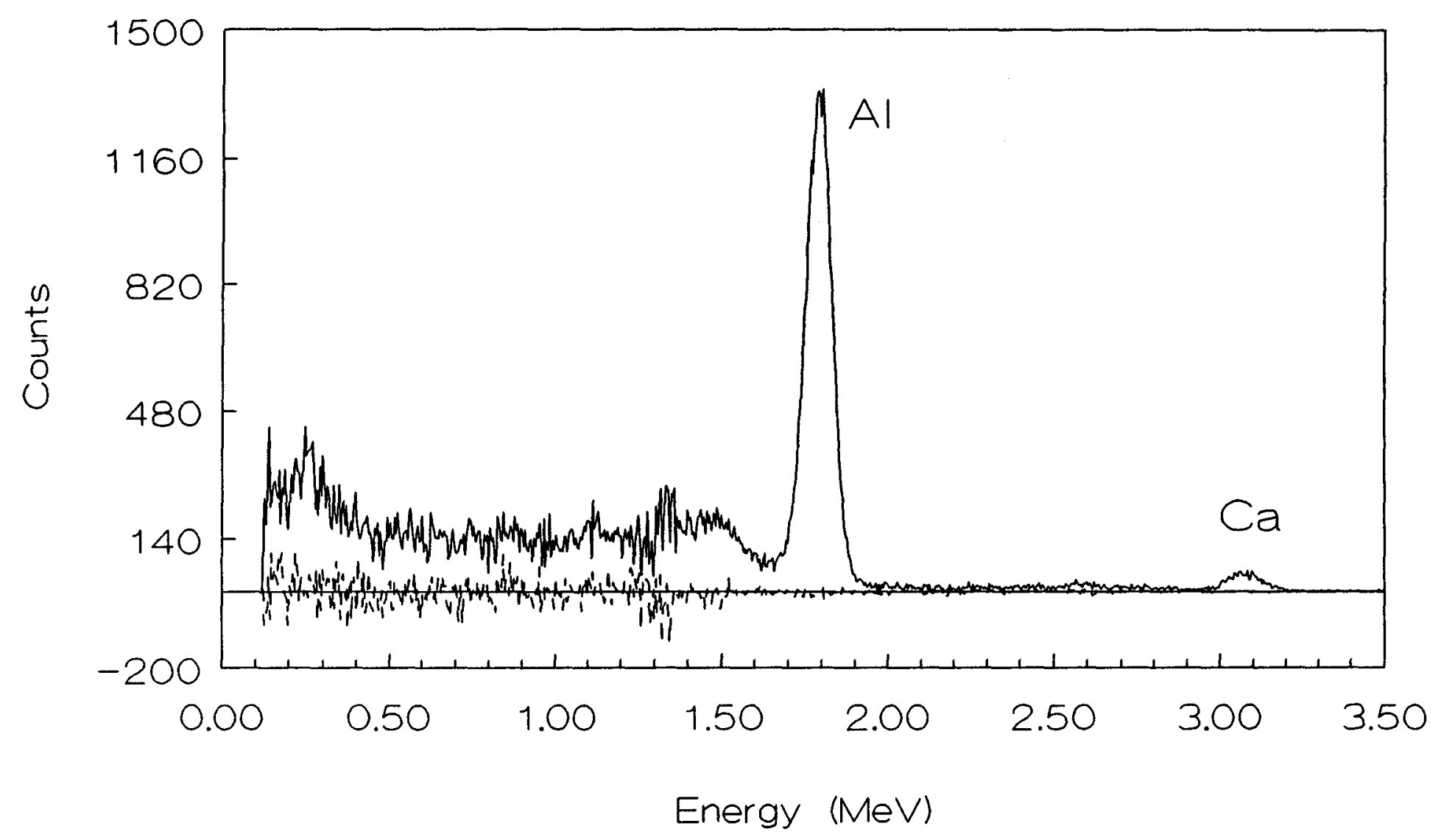

Figure 3.7: Comparison of Neutron Sources: KN-Accelerator. 
aluminum peaks by the number of moles of these elements present in the samples. The "quality" of the neutron beam, based on the criteria of high thermal output, will thus be established by determining the relative interference effects.

The spectra from beam port 2, Figure 3.5, show clearly the production of ${ }^{28} \mathrm{Al}$ from phosphorous and silicon. From these spectra, the thermal to fast $\left(>1.95 \mathrm{MeV}\right.$ ) neutron flux can be calculated. First, the net area under the ${ }^{28} \mathrm{Al}$ peak is measured using a simple sum of the counts under the peak, minus a linear fit to the background. From this value, the area of the aluminum peak, in a spectrum of an activated empty nalgene bottle, is subtracted. Assuming that this net area is a measure of the activity in the sample, from the decay of ${ }^{28} \mathrm{Al}$, and using the definition of activity:

$$
A=\sigma N \phi\left(1-e^{-\lambda y}\right.
$$

where $\mathrm{A} \quad$ = activity of sample

$\lambda=$ decay constant

$T_{1 / 2}=$ half-life of isotope $=\ln 2 / \lambda$

$\sigma \quad=$ cross section of the reaction

$\mathbf{N} \quad=$ number of atoms of element to be activated

$\mathrm{t} \quad=$ duration of irradiation

$\phi \quad=$ neutron flux 
the ratio of thermal to fast neutron flux becomes (assuming that the transfer time is the same for all samples):

$$
\frac{\phi_{\text {th }}}{\phi_{\text {fass }}}=\frac{\text { net area }}{\text { net } \operatorname{area}_{P}<\sigma_{P l}>n_{P}}
$$

where $\sigma_{\mathrm{Al}} \quad=$ cross section for the ${ }^{27} \mathrm{Al}(\mathrm{n}, \gamma)^{28} \mathrm{Al}$ reaction

$$
=0.23 \mathrm{~b},[36]
$$

$\left.<\sigma_{\mathrm{p}}\right\rangle=$ cross section for the ${ }^{31} \mathrm{P}(\mathrm{n}, \alpha)^{28} \mathrm{Al}$ reaction at $5 \mathrm{MeV}$ (assuming that the beam has energies from 1 to $10 \mathrm{MeV}$, the cross section at the middle energy is interpolated from the plot of $\sigma_{\mathbf{n}}$ versus energy.)

$$
=2 \mathrm{mb},[32]
$$

From this equation, the thermal neutron flux is calculated to be only $40 \%$ of the fast ( $>1.95 \mathrm{MeV}$ ) flux. When the same samples were irradiated at beam port 4, the spectra in Figure 3.6 were obtained. Note that both the graphs from the reactor beam ports, and that from the $\mathrm{KN}$-accelerator, do not have the nalgene aluminum peak subtracted from the aluminum, phosphorous or silicon peak. Only a minor activation of ${ }^{28} \mathrm{Al}$ from phosphorous was detected from beam port 4, and for this beam, the fast neutron flux was calculated (in a similar fashion as previously mentioned) to be $1.1 \%$ of the thermal flux. The flux above $4 \mathrm{MeV}$, ie. with the possibility of activating ${ }^{28} \mathrm{Si}$, is only $0.94 \%$ of 
Neutron

Sources

Beam Port 2

Beam Port 4

KN-

Accelerator
Thermal Flux

1

1

1
$>1.95 \mathrm{MeV}$

Flux

2.5

0.011

$\sim 0$
$>4.0 \mathrm{MeV}$

Flux

0.74

0.0094

$\sim 0$

Table 3.1: Relative Flux Intensities of Neutron Sources. 
the thermal flux. For the case of silicon, a cross section at $5 \mathrm{MeV}$ of $20 \mathrm{mb}$ [32] for the ${ }^{28} \mathrm{Si}(\mathrm{n}, \mathrm{p})^{28} \mathrm{Al}$ reaction is assumed. The relative flux intensity measurements for both reactor beam ports are compared in Table 3.1. In conclusion, beam port 4 is found to have both a higher total neutron flux (see Sect. 3.1), and a higher thermal component than beam port 2. Furthermore, the results from both beam ports can be compared to expected fission spectrum from a nuclear reactor, that follows the relationship [39b]:

$$
N \sim \sqrt{E} e^{-0.775 E}
$$

where $\mathbf{N}=$ measured signal

$$
\mathbf{E}=\text { neutron energy. }
$$

Thus, the ratio of neutrons with energies over $1.95 \mathrm{MeV}$ to those with energies over $4.0 \mathrm{MeV}$, for an unfiltered reactor beam, is approximately 4.0 . For beam port 2 , the ratio is 3.4 , confirming that the beam has no filtration components. On the other hand, the silicon and sapphire crystal filter in beam port 4 serve to reduce the proportion of neutrons over $1.95 \mathrm{MeV}$ relative to those over 4.0 $\mathrm{MeV}$, as shown by the ratio of 1.17 .

Similar samples, with different chemical weights, were irradiated using the $\mathrm{KN}$-accelerator. The resulting spectra showed no interferences from phosphorous (see Fig. 3.7). This result is expected since, as previously stated, the kinematics of the ${ }^{7} \mathrm{Li}(p, n)^{7} \mathrm{Be}$ reaction should not allow the activation of any 
interference reactions.

Thus, the accelerator seemed to be the most promising neutron source, based on its negligible phosphorous activation. However, the practical difficulties with using this modality, due both to its distance from the detection area and the problem in obtaining beam time, impede its usefulness. Consequently, all further experiments were conducted using the better of the two reactor beams, ie. beam port 4. For this study, it is the best compromise on the basis of ease of access, thermal neutron output and neutron flux. However, an eventual patient facility might revert back to an accelerator-based system since this modality could be transportable, if a portable accelerator is used. 


\section{Chapter IV}

\section{Calibration Curve and Minimum Detection Limit}

\subsection{Initial Experiments}

The presence of aluminum impurities, in the environment surrounding the detectors, was investigated in a preliminary experiment. Spectra were obtained to examine the type of radioactive elements present in the background before and after reactor "start-up" time. The premise is that the operation of the reactor itself may cause various radioactive isotopes to build up in the building. The detectors are in a concrete room with a curved entrance way, but no closed door, such that activated elements in the environment can be detected. The main concern are that the isotopes releasing $\gamma$-rays lying at or near the aluminum and calcium peaks, can cause increased uncertainty in the area measurements.

For each series of the activated phantom measurements, at least one background spectrum is accumulated. In these spectra, the presence of a peak at the aluminum position is detected. The question arises whether this line is actually due to aluminum in the building, activated by neutrons produced in the reactor, or perhaps is due to the decay of an isotope from the decay 
Background Before Reactor Start Up

(counts)

$688 \pm 52$

$647 \pm 62$

$619 \pm 59$

$705 \pm 74$

$605 \pm 58$
Background After Reactor. Start Up (counts)

$613 \pm 50$

$726 \pm 66$

$591 \pm 51$

$749 \pm 69$

$722 \pm 53$

$601 \pm 53$

$604 \pm 49$

$482 \pm 62$

$698 \pm 58$

$544 \pm 55$

$504 \pm 49$

Average After:

$621 \pm 92$ counts

Difference Between Background Sets: $32 \pm 44$ counts

Combined Mean: $631 \pm 80$ counts

SEM: 21 counts

Table 4.1: Background Aluminum Peak Measurements. 
chain of some naturally present radioactive element.

Table 4.1 shows the net areas under the background peaks from each of the spectra. Typically, results are quoted with their standard deviation (standard error of estimate, SEE) :

$$
S E E=0 \sqrt{\frac{\sum X_{i}^{2}-N \bar{X}^{2}}{N-1}}
$$

The standard error of the mean of the average background value, SEM, was used to calculate the uncertainty in the net aluminum peak areas (background subtracted), for all further results.

$$
S E M=\frac{\sigma}{\sqrt{N-2}}
$$

The average area before reactor start up is $(653 \pm 43)$ counts while after start up it is $(621 \pm 92)$ counts. The first observation is that these values are not statistically different as demonstrated by the fact that their difference is $(32 \pm 44)$ counts. The uncertainty in the difference is calculated according to Snedecor and Cochran [40b], for a group of unequal sizes. The equations:

$$
\text { Pooled } s^{2}=\frac{s_{\left\langle x_{1}\right\rangle}{ }^{2}\left(n_{1}-1\right)+s_{\left\langle x_{2}\right\rangle}{ }^{2}\left(n_{2}-1\right)}{\left(n_{1}-1\right)+\left(n_{2}-1\right)}
$$




$$
s_{\left\langle x_{1}>-<x_{2}>\right.}=\sqrt{s^{2}\left(\frac{n_{1}+n_{2}}{n_{1} n_{2}}\right)}
$$

are used to verify the assumption that the background values are not statistically different, implying that the variance of both groups is the same. The calculated difference seems to imply that the background peak is due to a naturally present isotope and thus not a product of the reactor operation. Furthermore, if at least part of the counts in the peak were related to the reactor's operation, a higher area should be found in the spectra taken after the start up. This however is not found to be the case.

The isotope ${ }^{214} \mathrm{Bi}$, in the ${ }^{298} \mathrm{U}$ decay chain, emitting a $\gamma$-ray at 1.7645 $\mathrm{MeV}$ (intensity $16 \%$ ) is suspected to be the cause of the background peak. In Figure 4.1, a typical background spectrum is shown. $\mathrm{A}^{60}$ Co source was used to calibrate the energy scale. The presence of ${ }^{214} \mathrm{Bi}$ is confirmed by the finding of a peak in the region of $0.6093 \mathrm{MeV}$, which is another $\gamma$-ray energy released by this isotope (intensity $47 \%$ ). The implication of this interference is that the choice of detector shielding, used to reduce the background signal, should involve a material from which ${ }^{238} \mathrm{U}$ has been removed.

Using a method of measuring the relative interference of this photopeak, similar to that used to calculate the nalgene aluminum contamination (see Sect. 2.3), it is established that this background peak would equate to 


\section{Background Spectrum bkg2805b.cat}

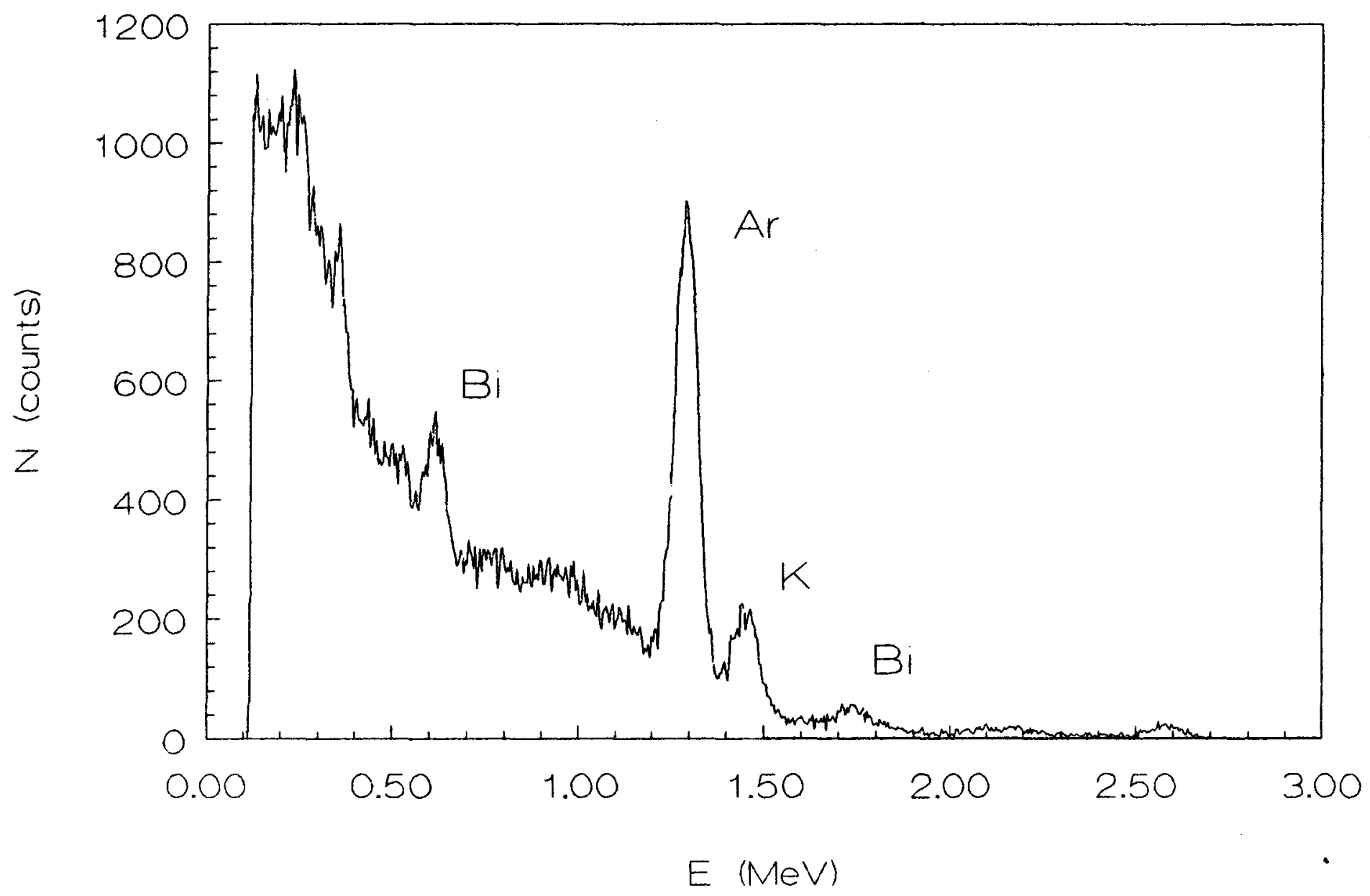

Figure 4.1: Typical Background Spectrum. 
approximately $3.5 \mathrm{mg}$ of $\mathrm{Al}$ interference. However, this result is not directly used since the net area under the background peak can be subtracted instead from the phantom measurements, thus removing the interference. The background area subtracted from the results is an average of the background peaks observed before and after reactor start up, ie. $(631 \pm 21)$ counts. No significant background peak at the calcium position was observed. Thus, no background will be subtracted from the area measured at the $3.08 \mathrm{MeV}$ line in the phantom spectra.

The background spectra, taken during the experiments, also show a large peak at $1.29 \mathrm{MeV}$, which seems to increase with increasing time from start up of the reactor. This peak is due to the presence of ${ }^{41} \mathrm{Ar}$ building up in the air from the neutron capture of ${ }^{40} \mathrm{Ar}$. The position of the ${ }^{41} \mathrm{Ar}$ line is such that it would interfere with the measurement of the $1.36 \mathrm{MeV}$ peak from the ${ }^{24} \mathrm{Na}$ decay. However, even though ${ }^{24} \mathrm{Na}$ will be activated during neutron activation of the hand, its detection is not part of this study. Thus, the presence of ${ }^{41} \mathrm{Ar}$ is not considered to be an interference.

The second group of preliminary experiments consisted of investigating the presence of isotopes in the phantoms that have decay lines at or near that of aluminum and calcium. These isotopes would have slightly shorter or longer half lives such that their decay would interfere with the measurements of the net area under the peaks. 
The resin phantoms were individually irradiated and six consecutive spectra were accumulated over a period of 20 minutes. The analysis of the aluminum and calcium photopeaks in each sequential spectrum will give information on the decay of the isotopes. From theory, the net area under the peaks should decay exponentially with time. Thus, a plot of the photopeak area as a function of time should follow the exponential relationship:

$$
A=\frac{N_{0}}{\lambda} e^{-\lambda x}\left(1-e^{-\lambda e_{c}}\right)
$$

where $\mathbf{A}=$ net area under photopeak

$\mathbf{N}_{0}$ = number of activated isotopes present after the transfer time

$\lambda=$ decay constant

t = time from beginning of the counting period

$t_{c}$ = actual counting interval

The decay of the calcium peak, in a typical phantom, is plotted in Figure 4.2. Since the counting intervals are of irregular lengths, the area measured under the peak must be corrected by dividing by the $\left(1-\exp \left(-\lambda t_{\text {c }}\right)\right)$ term, where the accepted half life of 8.72 minutes is used. Thus, the corrected area is plotted as a function of the time from the beginning of the counting period. The average half life calculated from the decay of the 0.5 to $50 \mathrm{mg} \mathrm{Al}$ phantoms is $(9.0 \pm 0.6)$ minutes, which is not statistically different from the actual half life of $\mathbf{8 . 7 2}$ minutes. The values are thus sufficiently close to 


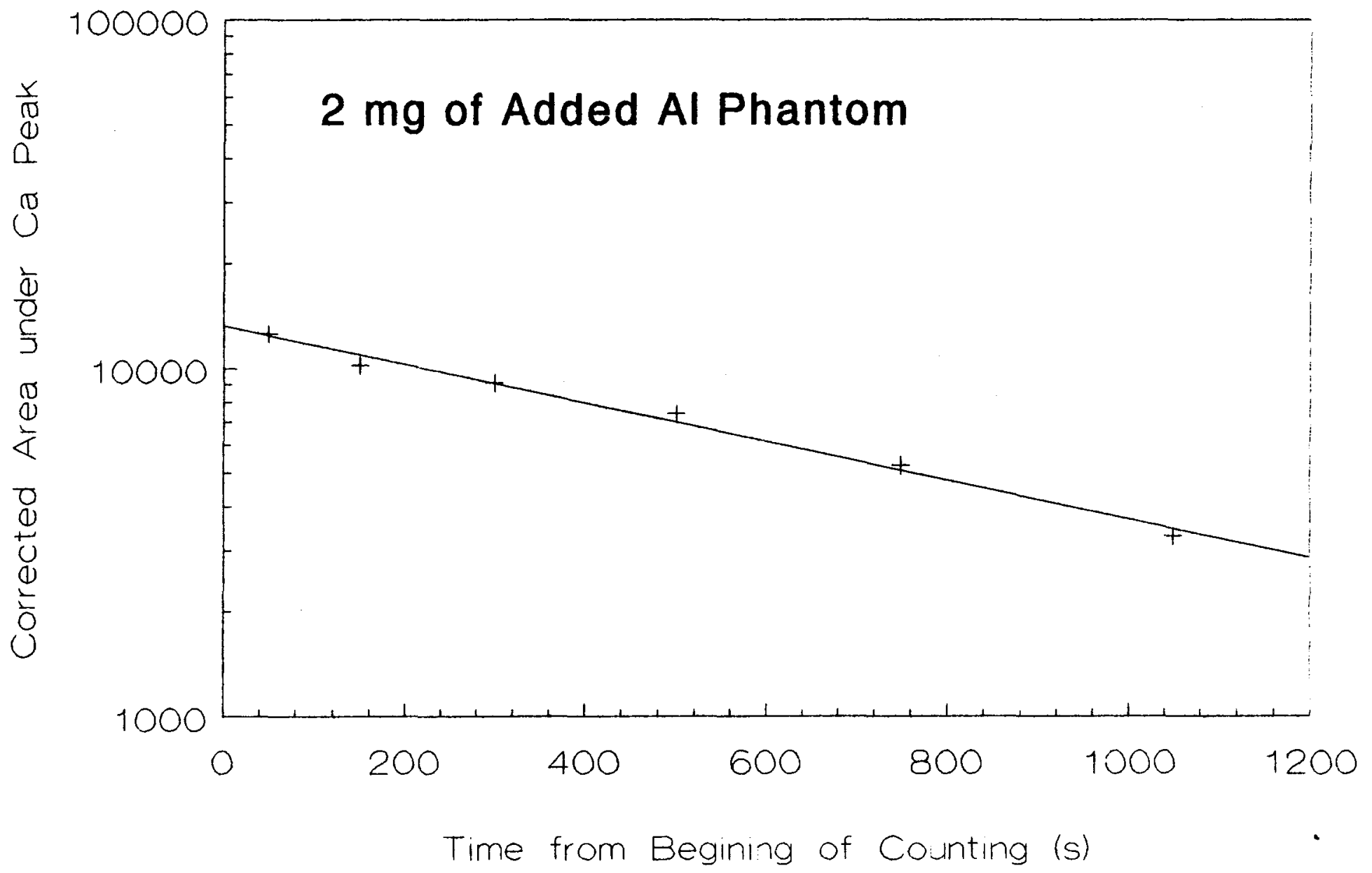

Figure 4.2: Typical Decay of the Calcium Peak with Time. 
assume that no other isotopes present are decaying with a similar energy. The exponential curve would have been distorted otherwise.

A similar graph cannot be obtained for the ${ }^{28} \mathrm{Al}$ decay since its half life is only $\mathbf{2 . 3}$ minutes, such that its presence is masked by background after approximately 5 minutes. However, the absence of a measurable peak at the $1.78 \mathrm{MeV}$ position, after this period of time, indicates that no other longer lived isotopes decay at this energy. Shorter lived isotopes would be of no concern in this study since they would decay nearly completely during the transfer time, and if still present, would only interfere for a negligible fraction of the counting time.

\subsection{Calibration Curve and Minimum Detection Limit}

The series of six resin phantoms with $0,0.5,2,5,20$, and $50 \mathrm{mg}$ of added aluminum were irradiated using beam port 4 as the neutron source. Figure 4.3 shows the $\gamma$-ray energy spectra from two phantoms with widely different aluminum content, 0.5 and $50 \mathrm{mg} \mathrm{Al}$. From these spectra, the net areas of aluminum were measured and the background aluminum area was subtracted. The calcium peak was then fitted separately, and an aluminum to calcium ratio was calculated. This irradiation series was repeated three times in order to increase the precision in our results. These data are shown 


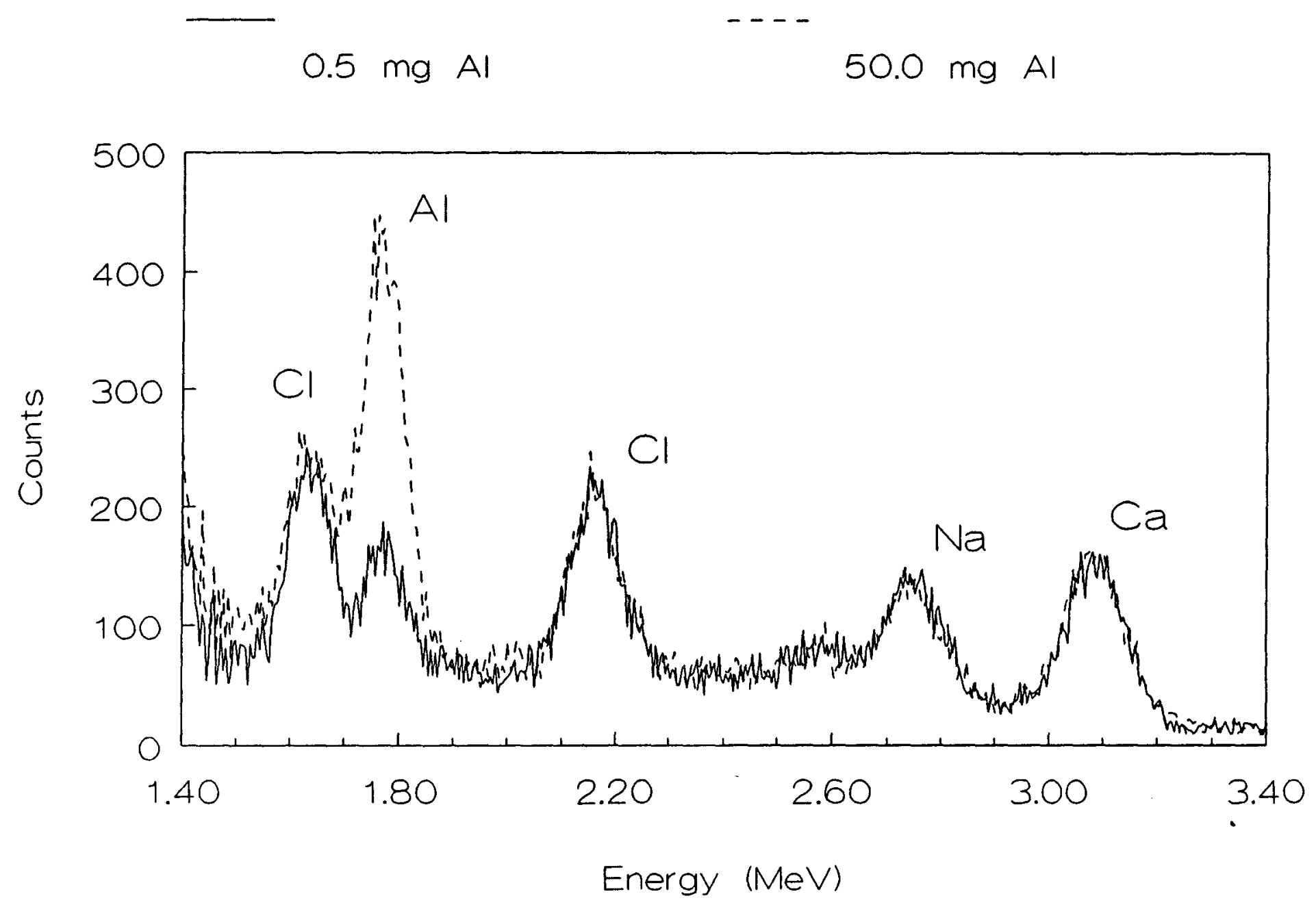

Figure 4.3: Spectra for Two Phantoms of Widely Different Aluminum Content. 
in Table 4.2.

The resulting aluminum to calcium ratios were plotted as a function of the added aluminum weight in the phantoms, in Figure 4.4. The equation governing this calibration curve is:

$$
\frac{A l}{C a}=(0.434 \pm 0.014)+(0.02581 \pm 0.00061) A l(m g)
$$

The expected aluminum to calcium ratio for no added aluminum, ie. the $y$ intercept, should ideally be negligible. This result assumes that the products used to create the phantoms have no inherent aluminum impurities and that the protocol for the phantom formation introduces no contaminations. However, the experimental $y$-intercept, although in good agreement with the data, is not statistically a negligible quantity. Section 4.3 will investigate the source of the aluminum signal, when no chemical aluminum is added.

From the calibration curve, a minimum detection limit (MDL) can be calculated, as defined in section 2.2. Instead of simply using one uncertainty value for a low aluminum concentration point, as in the definition, an average of all the uncertainty values for the $\mathrm{A} / \mathrm{Ca}$ ratio in the $0,0.5$, and $2 \mathrm{mg}$ of $\mathrm{Al}$ phantoms is entered into the calculation. This average becomes 0.0358 , and combined with the slope of the calibration curve, gives an MDL of $2.8 \mathrm{mg}$ of $\mathrm{Al}$. From Table 4.2, a $2 \mathrm{mg} \mathrm{Al}$ phantom is seen to be barely distinguishable from lower concentration phantoms, whereas $5 \mathrm{mg}$ of $\mathrm{Al}$ is clearly different. Thus, 
Phantom 0

Net $\mathrm{Al}$ peak

(counts)

$0 \mathrm{mg} \mathrm{Al}$

Phantom 1

$0.5 \mathrm{mg} \mathrm{Al}$

Phantom 2

$2 \mathrm{mg} \mathrm{Al}$

Phantom 3

$5 \mathrm{mg} \mathrm{Al}$

Phantom 4 $20 \mathrm{mg} \mathrm{Al}$

Phantom 5 $50 \mathrm{mg} \mathrm{Al}$
$1319 \pm 111$

$1624 \pm 113$

$1424 \pm 113$

$1635 \pm 123$

$1606 \pm 101$

$1402 \pm 95$

$2049 \pm 139$

$1892 \pm 117$

$1655 \pm 114$

$2413 \pm 135$

$2402 \pm 125$

$1803 \pm 117$

$4523 \pm 165$

$3784 \pm 127$

$3035 \pm 130$

$7082 \pm 165$

$6618 \pm 143$

$5254 \pm 145$
Ca peak

(counts)

$3504 \pm 140$

$3375 \pm 119$

$3324 \pm 113$

$3885 \pm 159$

$3566 \pm 129$

$3060 \pm 110$

$4899 \pm 180$

$3543 \pm 114$

$3269 \pm 108$

$4643 \pm 182$

$3604 \pm 111$

$3270 \pm 115$

$4600 \pm 149$

$4210 \pm 132$

$3218 \pm 110$

$4035 \pm 166$

$3778 \pm 124$

$3140 \pm 113$
$\mathrm{A} / \mathrm{Ca}$

$0.376 \pm 0.035$

$0.481 \pm 0.038$

$0.428 \pm 0.037$

Average:

$0.429 \pm 0.052$

$0.421 \pm 0.036$

$0.450 \pm 0.033$

$0.458 \pm 0.035$

Average:

$0.443 \pm 0.020$

$0.418 \pm 0.032$

$0.534 \pm 0.037$

$0.506 \pm 0.039$

Average:

$0.486 \pm 0.061$

$0.520 \pm 0.035$

$0.667 \pm 0.040$

$0.551 \pm 0.041$

Average:

$0.579 \pm 0.077$

$0.983 \pm 0.048$

$0.899 \pm 0.041$

$0.943 \pm 0.052$

Average:

$0.942 \pm 0.042$

$1.755 \pm 0.083$

$1.752 \pm 0.069$

$1.673 \pm 0.076$

Average:

$1.727 \pm 0.046$

Table 4.2: Aluminum and Calcium Peaks from Phantom Spectra. 


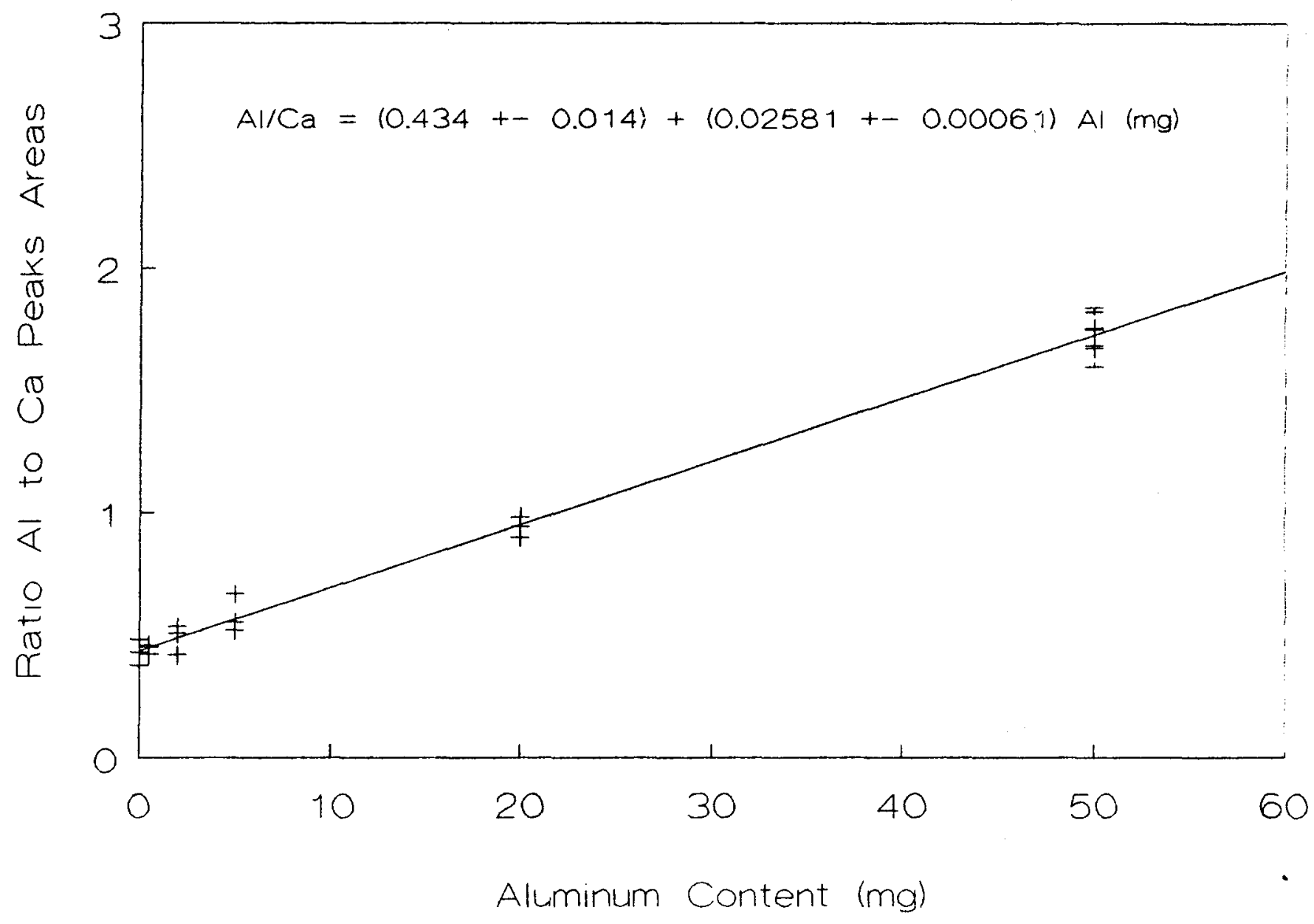

Figure 4.4: Calibration Curve. 
a minimum detection limit lying somewhat between these two points would agree with the data.

The final qualification needed to properly describe the MDL is the dose rendered to the phantoms during the 3 minutes irradiation. This point will be discussed in Chapter 5.

\subsection{Aluminum Impurities and Phosphorous Interference in Phantoms}

From the previous section, it was determined that even in the $0 \mathrm{mg} \mathrm{Al}$ phantom, a significant aluminum peak was present, above the background level. This finding was thought to be due to either an aluminum contamination in the phantom, or to the activation of phosphorous by fast $(>1.95 \mathrm{MeV})$ neutrons. The aluminum impurity could be found in the polyester resin itself or in the added bone ash. The latter has no guarantee of purity since it comes from animal bones, and is used mainly for pottery where, needless to say, aluminum contamination is not a main concern. The other added chemicals are of a high laboratory-type purity.

First to investigate the provenance of the possible impurity, a pure resin phantom, and a resin and bone ash phantom were created. The rcais and bune ash quantities, and the protorn :....... =ake the phantoms, remained unchanged frasere previous series of phantoms. The new phantoms, as well 
as the phantom with no added aluminum (Phantom 0), were irradiated in order to obtain their relative aluminum content. The presence of phosphorous interference was measured by first wrapping the phantom side exposed to the neutron beam with cadmium of approximately $1 \mathrm{~mm}$ in thickness, and then irradiating the phantom. The cadmium layer will absorb most neutrons with energies below its resonance of approximately $0.5 \mathrm{eV}$ [36], thus preventing the activation of ${ }^{27} \mathrm{Al}$. Since the thermal cross section of cadmium is $(2450 \pm 30)$ b [36], the ratio of the transmitted thermal neutron flux to the original flux is $0.001 \%$, according to:

$$
\frac{\phi}{\phi_{0}}=e^{-\frac{\rho N_{A}}{M} \alpha x}
$$

where $\phi=$ transmitted flux

$\phi_{0} \quad=$ original flux

Q = density

$\mathbf{N}_{\mathrm{A}}=$ Avogadro's number

$\mathbf{M}=$ molar mass

$\sigma \quad=$ thermal cross section

$\mathbf{x}=$ cadmium thickness

Consequently, the resulting spectra will show only the production of ${ }^{28} \mathrm{Al}$ from the phosphorous activations. The activation of silicon in the ${ }^{28} \mathrm{Si}(\mathrm{n}, \mathrm{p})^{28} \mathrm{Al}$ 
reaction could also occur if neutrons with energy greater than the threshold of $4 \mathrm{MeV}$ are present. However, since past experiments have shown that the fast component of the beam is a small percentage of the thermal component (see Table 3.1), this activation should be improbable. Furthermore, silicon should be considerably less common in the phantoms than phosphorous.

In this series of experiments, each phantom was irradiated three times, with and without the cadmium wrapping. Table 4.3 shows the net aluminum peak measurements (background of $(631 \pm 21)$ counts subtracted).

The average aluminum area from all three cadmium wrapped phantoms gives a measure of the phosphorous interference in a typical resinbased phantom. If this value, $(27 \pm 13)$ counts, is divided by a rough average of the calcium peak areas (from Table 4.2), 3718 counts, the phosphorous activation is found to account for approximately 2 to $3 \%$ of the calibration curve's $y$-intercept. Thus, even if the phosphorous interference is not an entirely negligible quantity, it is responsible for only a small fraction of the aluminum signal, when no added aluminum is introduced.

The difference in the aluminum peak areas from the cadmium wrapped and non-wrapped irradiations gives a measure of the net ${ }^{27} \mathrm{Al}$ activation. For the resin phantom, the difference shows negligible activation of aluminum, implying that the phantom aluminum contamination should instead be in the bone ash. This deduction is proven by the difference in aluminum areas of the 


\section{Al Peak (Background Subtracted) (counts)}

Resin

Phantom
Resin and

Bone Ash

Phantom

No Cadmium

Wrapping

Cadmium

Wrapped

$$
\begin{aligned}
& 132 \pm 71 \\
& 124 \pm 105 \\
& -22 \pm 61
\end{aligned}
$$

$1712 \pm 97$

$1701 \pm 86$

$1398 \pm 109$

$1370 \pm 84$

$1796 \pm 137$

$1624 \pm 113$

Average:

$78 \pm 87$

$21 \pm 70$

$20 \pm 66$

$52 \pm 90$

Average:

$31 \pm 19$

Average:

$1594 \pm 194$

$78 \pm 90$

$64 \pm 77$

$-103 \pm 59$

Average:

$13 \pm 101$
Average:

$1606 \pm 200$

$\Delta$ (Non-

Wrapped and Wrapped Phantoms)

$47 \pm 89$

$1556 \pm 214$

$1568 \pm 203$

$51 \pm 66$

$0.7 \pm 69$

$64 \pm 65$

Average:

$39 \pm 33$

Table 4.3: Determination of $\mathrm{Al}$ Impurity and $\mathrm{P}$ Interference. 
resin and bone ash phantom, which shows a significant aluminum signal. Since this difference statistically agrees with that of the phantom with $0 \mathrm{mg}$ of added $\mathrm{Al}$, the assumption that no impurity exists in the other chemicals is justified. Dividing the net bone ash aluminum area value (resin area subtracted) by the average calcium area, the activation of aluminum in the bone ash is observed to account for the expected value of approximately $97 \%$ of the $y$-intercept, within the uncertainty values of the data.

The conclusions are therefore that the fast $(>1.95 \mathrm{MeV})$ neutron fraction of the beam activates only a negligible phosphorous interference, such that beam port 4 can be a feasible modality for further work. Secondly, the resin phantoms inherently contain a significant aluminum component in the bone ash, before any chemical aluminum is further added. This impurity can only be reduced in a next generation of phantoms (see Chap. 7), replacing the bone ash with some aluminum-free material.

The weight of the aluminum contamination in a phantom can be estimated using calculations similar to the determination of the nalgene bottle impurity (see Sect. 2.3). The impurity is thus calculated to be approximately $9 \mathrm{mg}$ of Al. Therefore, instead of removing the source of impurity (new phantoms could not be created due to time constraints), the contamination is simply accounted for, and its weight will be added to the known quantity of added aluminum. Thus, a modified calibration curve can be obtained, by 


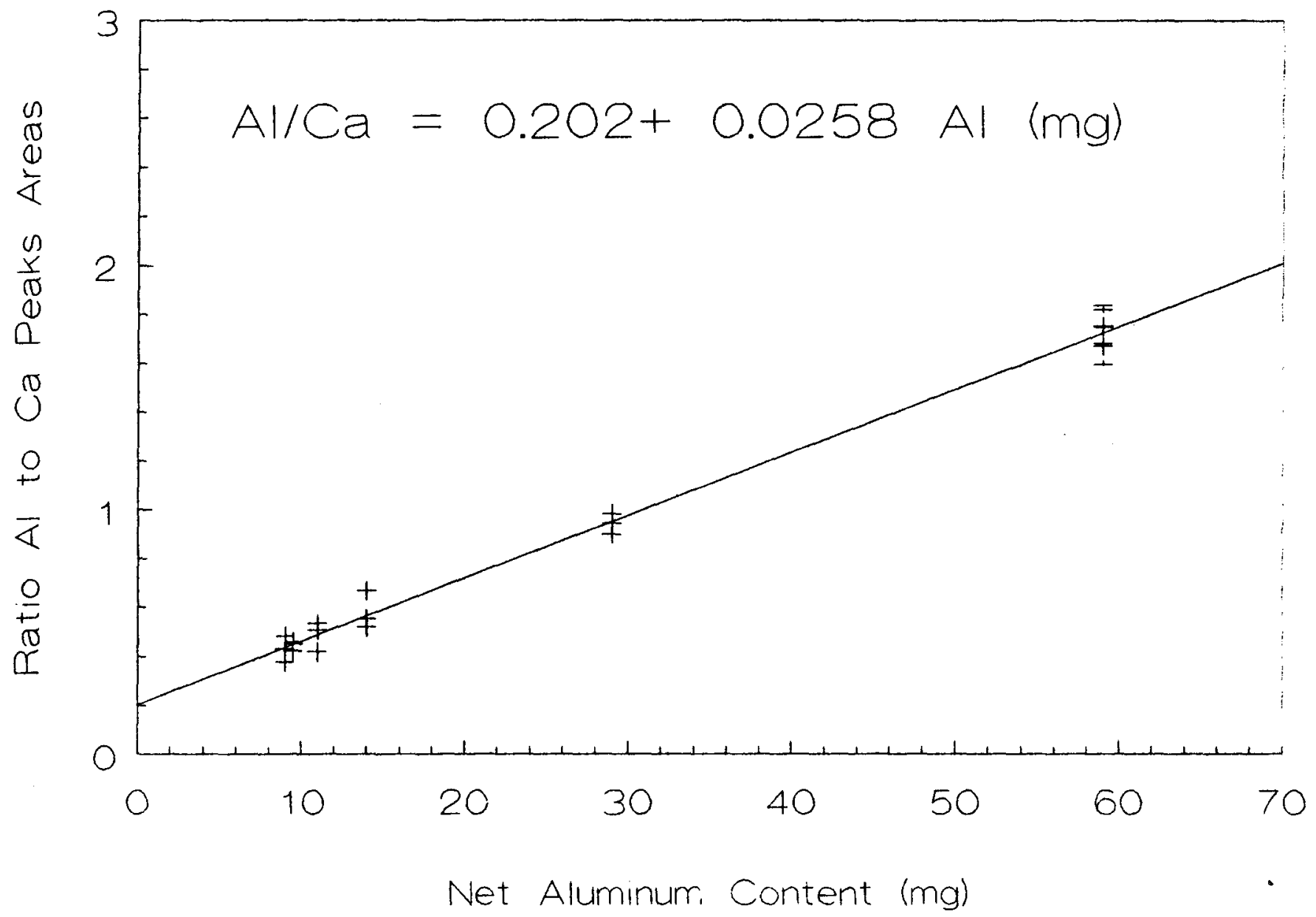

Figure 4.5: Corrected Calibration Curve. 
simply shifting the line horizontally by $9 \mathrm{mg}$ of $\mathrm{Al}$, as seen in Figure 4.5. The shift, however, does not remove the expected portion of the y-intercept due to the aluminum contamination. The fact that the calculation of the $\mathrm{Al}$ impurity weight is only an approximation (see Sect. 2.3) would explain this discrepancy. 


\section{Chapter V}

\section{Dose Measurements}

\subsection{Description of the Anderseon-Braun Remmeter}

In neutron activation analysis, the neutrons that would come in contact with a hand would not only cause the activation of various elements, but also produce radiation damage, due to their interaction with the tissues. This damage is measured as the dose delivered to the patient, during the irradiation. For subsequent patient studies, it would be imperative that the dose due to this procedure be maintained at the minimum possible. Thus, careful dosimetry of the modality used to perform the activations should be accomplished.

For this preliminary study, the dose delivered to the resin phantom, in beam port 4, is measured using an Andersson-Braun remmeter (Tracerlab NP1 portable neutron monitor [42]), colloquially called a "Snoopy". This monitor is a $\mathrm{BF}_{3}$ proportional counter with a polyethylene moderator. It functions by measuring the ionization caused by the $\alpha$-particles emitted when the ${ }^{10} \mathrm{~B}(\mathrm{n}, \alpha)^{7} \mathrm{Li}$ reaction occurs. The resulting electrical pulses will then be converted to a DC current. The $\mathrm{BF}_{3}$ counter efficiency is flat for thermal 
neutrons, and falls off rapidly above $1 \mathrm{eV}$. Thus, in order to detect fast neutrons (ie. energy greater than thermal), a 2.25" thick outer layer of polyethylene is used as a neutron moderator. This material is chosen due to its high hydrogen content which thermalizes neutrons by elastic scattering. A $0.25^{\prime \prime}$ thick ${ }^{10} \mathrm{~B}$ attenuator layer reduces the thermal neutron flux by absorbing the neutrons, before they reach the counter, with a cross section proportional to the square root of the neutron energy. Finally, the monitor also has a $0.75^{\prime \prime}$ thick layer of polyethylene that acts as an inner moderator. For neutron energies between thermal and $15 \mathrm{MeV}$, the output pulse rate for the detector will be proportional to the dose rate delivered to the tissue.

The monitor has been measured, by Sokolowski [40], to have a directionality variation of as little as $20 \%$. Its accuracy is stated [42] to be $\pm 10 \%$ from thermal energies to $15 \mathrm{MeV}$, though Sokolowski has noted some response variations with neutron energy.

\subsection{Dosimetry Protocol}

The experiments, measuring the dose absorbed by the phantoms, consisted of first positioning the monitor in beam port 4 . In further experiments (see Chap. 6), activation foils will be irradiated, in this beam port, in order to obtain information on the neutron flux at various energies. These 
flux measurements can then be used to calculate the dose due to an irradiation with this beam. Thus, it was chosen to directly measure the dose using the Snoopy monitor at the activation foil position, ie. near the beam exit, in order to permit comparison of the dose values. The monitor was also moved back to the phantom position near the beam stop, for one measurement, such that a scaling factor between the two positions could be obtained.

At the activation foil position, the monitor was $22 \mathrm{~cm}$ in front of the beam opening, and its center was at a height of approximately $103 \mathrm{~cm}$ from the cave floor, ie. at the beam center's height (see Fig. 5.1). The monitor's position was marked out and, as previously mentioned, only changed once throughout the experiment. Consequently, little variation in orientation of the monitor was expected. It was also attempted to maintain the monitor face perpendicular to the beam at all time. The sensitivity range of 0 to 2000 $\mathrm{mrem} / \mathrm{hr}(20 \mathrm{mSv} / \mathrm{hr})$ was chosen since it was reported by Sokolowski to be the only range at which the scaler output could be used.

The second monitor pasition was directly in front of the beam stop. The monitor was at the same height from the cave floor as in the first location, but there was now $119 \mathrm{~cm}$ between the monitor face and the beam opening, ie. 97 $\mathrm{cm}$ between both monitor positions. This second position had the monitor backed up against the beam stop such that Snoopy's face was approximately 15 to $20 \mathrm{~cm}$ in front of the phantom position. Due to the monitor's size, 

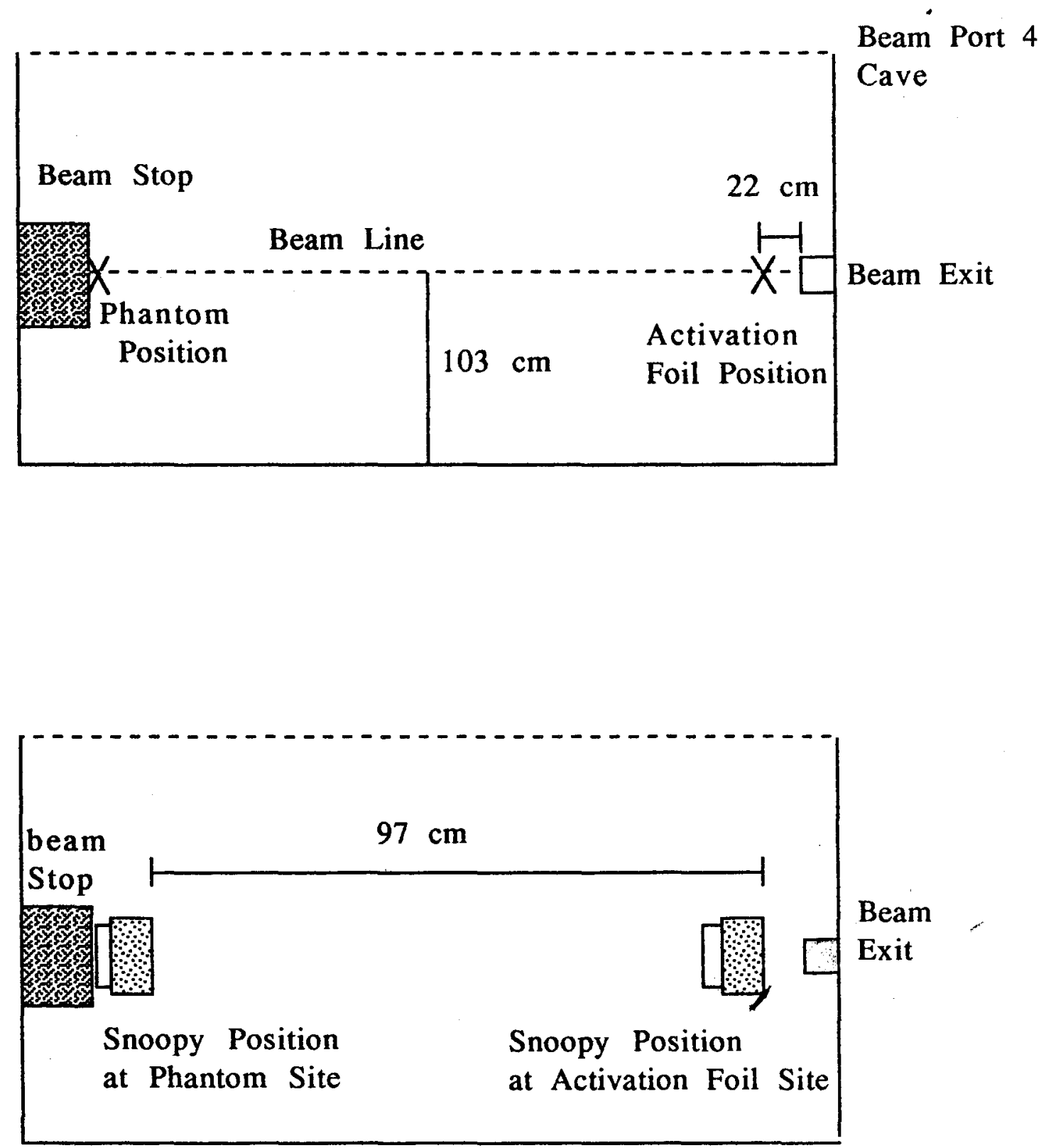

Figure 5.1: Snoopy Positioning in Beam Port 4. 
measurements could not be obtained closer to the actual phantom irradiation site.

Instrumentally, the experiment used a Logic Shaper and Delay (CI model 1455) that accepted the monitor's negative $1 \mathrm{~V}$ output and converted it to a positive $4 \mathrm{~V}$ output. This signal was then fed to a Scaler (CI model 871). The counting time was governed by a Timer/Scaler (CI model 1492).

\subsection{Dosimetry Results}

The experimental design consisted of gradually incrementing the reactor's output power, during the start up operation, such that at various steps, the counts resulting from the $100 \mathrm{~s}$ irradiation of the monitor were measured. The detector was allowed to settle for approximately 30 seconds, after an increase in reactor power, before a count reading was taken. The counting time was chosen since it allowed a sufficient amount of counts to be detected, at low power levels, such that reproducibility of the results was obtained. Furthermore, the percent uncertainty on the counting numbers was at minimum $3 \%$. The methodology was similar to that used in the study by Sokolowski.

The monitor's sensitivity of 8000 counts/mrem (800 counts/uSv) permitted the conversion of the counting rate to a dose equivalent rate. A 
correction for the difference in cross sectional area between Snoopy and the beam itself had to be included. The beam from beam port 4 has dimensions of approximately $2.5 \mathrm{~cm} \times 5.0 \mathrm{~cm}$, at the beam exit, whereas Snoopy has a circular active area of $20 \mathrm{~cm}$ in diameter. The dose measured by the monitor assumes that the radiation is distributed evenly over its surface area, which would only be correct if the beam area was comparable in size. Thus, for the beam dealt with in this study, the dose equivalent measured must be scaled by the ratio of the monitor to the beam cross sectional area. This ratio is calculated to be approximately 25 , at the activation foil site. The data acquired throughout the irradiations of Snoopy at the activation foil position, corrected for the cross sectional area, is plotted in Figure 5.2. As reported by Sokolowski, the monitor response becomes non-linear with increasing power level, after a certain output value. For beam port 2, this threshold was determined, by Sokolowski, to be $33 \mathrm{~kW}$. From the measurements obtained in beam port 4, the threshold would be considerably higher, perhaps at $400 \mathrm{~kW}$. The reason this beam port exhibits a larger linear region is that the fast neutron flux is considerably smaller than in beam port 2, as measured in Section 3.2. Thus, the dose rate for beam port 4 would be much lower than at the radiography beam port. For example, at the threshold value of $33 \mathrm{~kW}$, beam port 2 delivers a dose equivalent rate of $6.72 \mu \mathrm{Sv} / \mathrm{s}$ while beam port 4 only gives $3.59 \mu \mathrm{Sv} / \mathrm{s}$. It must also be noted that the Snoopy detector uses an 


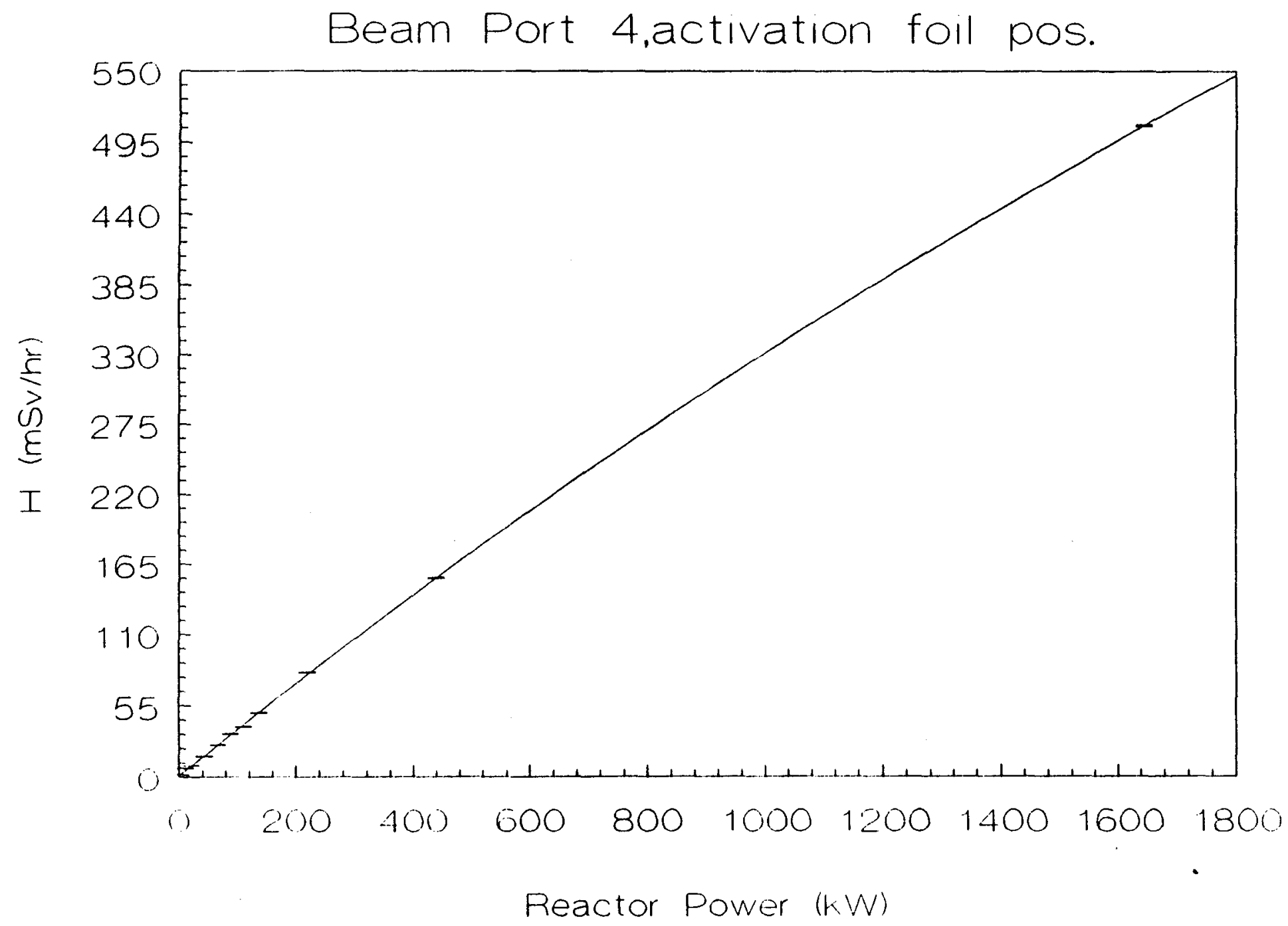

Figure 5.2: Snoopy Dose Equivalent Curve. 
average quality factor to convert the dose reading to a dose equivalent rate. The average value is dependent on the field in which the monitor has been calibrated. Therefore, for the dose equivalent measurements reported in this study, the quality factors used will be those preset in the monitor, based on ICRP 26 [23].

In the linear region of the dose curve, displayed in Figure 5.3, the equation relating dose equivalent rate to reactor power output is:

$$
H(m S w / h r)=1.509+0.346 \times \text { Reactor Power }(\mathrm{kW})
$$

Thus, extrapolating this curve to the maximum power output, $2 \mathrm{MW}$, at which the phantoms were irradiated, a dose equivalent rate of $693.5 \mathrm{mSv}$ per hour is obtained. For a 3 minute irradiation, the hand dose delivered to the patient would then be $34.7 \mathrm{mSv}$. At a power output of $164.38 \mathrm{~kW}$, the Snoopy monitor was moved back to near the phantom position, and a dose measurement was acquired. The ratio of the dose values at this power output, for the phantom site to the activation foil site was calculated to be 1.234 . Consequently at 2 MW, the hand dose at the phantom position, for a 3 minute irradiation, is 42.8 $\mathrm{mSv}$. The dose near the beam stop is noted to be actually larger than that near the beam exit. The reason is perhaps that there is backscattering of the neutrons back into the monitor, at the phantom position, due to the presence of the beam stop. The beam flux itself should decrease over the length of the 


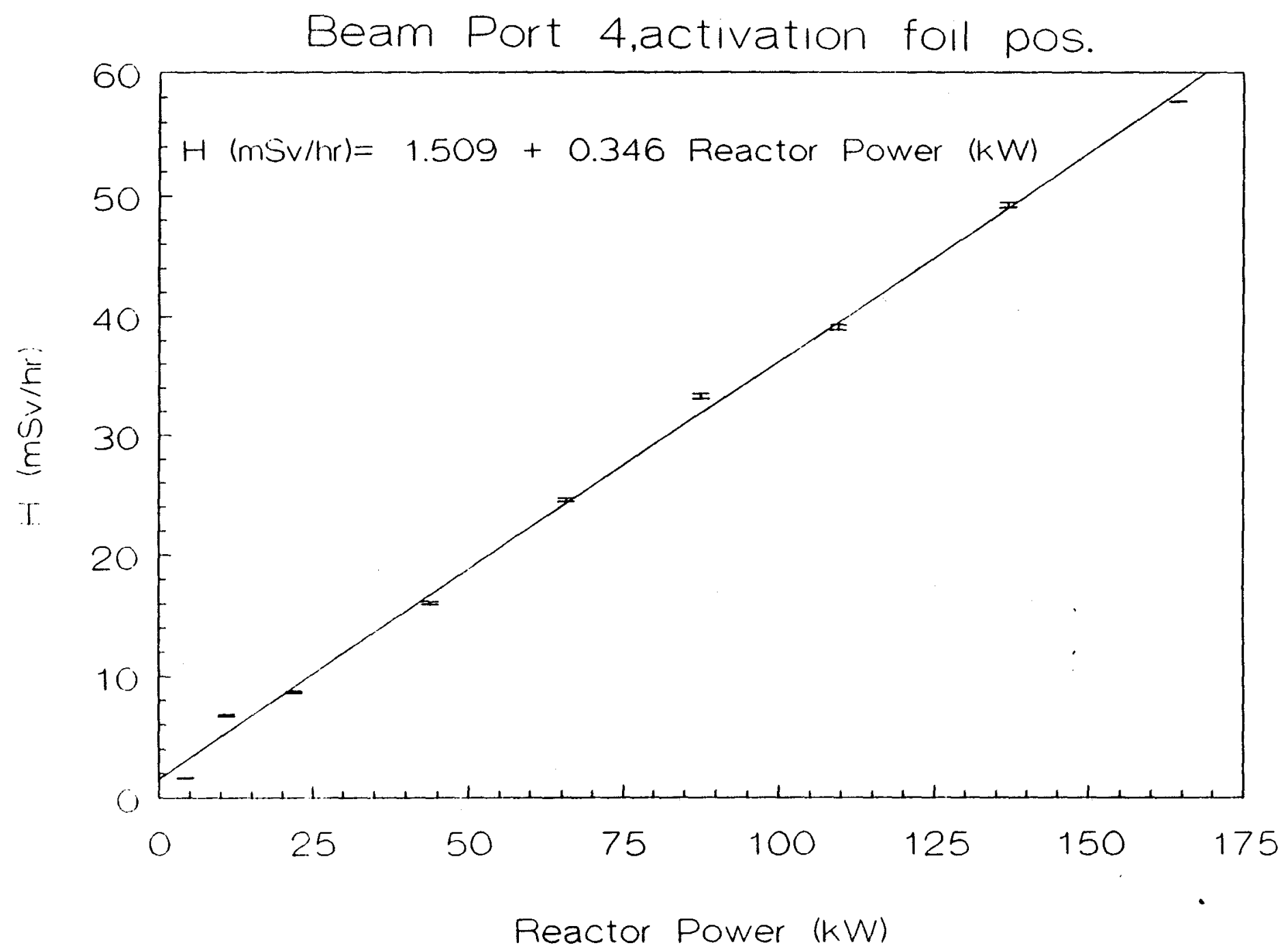

Figure 5.3: Snoopy Dose Equivalent Line. 
cave as an approximate function of the square of the ratio of distance between the beam source and the two monitor positions. The actual change in the flux between both dosimetric sites will be verified in Chapter 6 , using activation foils.

It must be noted that this dose equivalent value assumes that the neutron beam does not significantly diverge over the length of the cave, since the beam is well collimated. This implies that the ratio of cross sectional areas between Snoopy and the beam should be the same at both monitor positions. However, the inevitable divergence of the beam will serve to decrease the ratio of areas. Consequently, the dose equivalent value of $42.8 \mathrm{mSv}$ is considered as an upper limit on the actual dose due to the irradiation. A radiographic film of the beam could be obtained at the phantom position which would determine the beam size. From this information, an area ratio could be obtained for this second position.

The whole body dose associated with the hand dose of $42.8 \mathrm{mSv}$ can be calculated in a similar fashion as in Section 3.1. Assuming the hand represents $1.5 \%$ of both the total bone surface and skin of the body, and that both these organs have a weighting factor of 0.01 , the whole body dose becomes: 


$$
42.8 \times 0.015 \times 0.01+42.8 \times 0.015 \times 0.01=12.8 \mu S v
$$

The beam itself will contribute a dose to the patient since it is nearly impossible to shield the body completely from the radiation striking the hand. Above the beam stop, when the cave is open and the neutron beam is on, a dose of $25 \mu \mathrm{Sv} / \mathrm{hr}$ is measured with Snoopy. For a 3 minute irradiation, the dose equivalent is calculated to be $0.125 \mu \mathrm{Sv}$, which is an almost negligible value. Thus, it is inferred that the beam is well collimated. However, for a worst case situation, it could be assumed that the patient's body receives as much as $0.1 \%$ of the hand dose, ie. $42.8 \mu \mathrm{Sv}$. This fraction is chosen based on comparison with the Brookhaven study, which also uses a reactor based modality for neutron activation. In their case, a conservative estimate suggested that the beam contributed approximately $1 \%$ of the hand dose. In the present study, the whole body contribution of the beam appears to be somewhat smaller, as seen in the Snoopy measurement.

In conclusion, the total whole body dose due to a 3 minute irradiation, using beam port 4 , is the sum of the effective whole body dose associated with the hand exposure and the whole body dose due to the beam itself, ie. approximately $55.6 \mu \mathrm{Sv}$. In comparison to the annual background dose of over $2000 \mu \mathrm{Sv}$, the estimated dose equivalent due to this procedure is small.

It must be noted that this dose measurement only takes into 
consideration the neutron component of the beam. To a certain degree, there will also be $\gamma$-rays and other charged particles being emitted by the beam port. A more rigorous dosimetry must take these particles into consideration.

In Table 5.1, the minimum detection limit for aluminum in bone and the associated hand dose, from this study, are compared to the results from other groups performing similar measurements, as described in Section 1.3. The hand dose equivalent seems slightly larger than the results from other groups, whereas the MDL is comparable to the initial Birmingham and to the Swansea measurements. However, as previously mentioned, the measured dose is considered to be more of an upper limit than a representative estimate of the dose equivalent delivered to the hand. For comparison, Chapter 6 will provide a second dose equivalent measurement. Improvements to this system, as described in Chapter 7, should combine to lower both the dose and the MDL, in further measurements. 


\begin{tabular}{|c|c|c|c|}
\hline Site & Source & $\begin{array}{l}\text { Hand Dose } \\
(\mathrm{mSv})\end{array}$ & $\begin{array}{l}\mathrm{MDL} \\
(\mathrm{mg} \mathrm{Al})\end{array}$ \\
\hline Birmingham & $\begin{array}{l}{ }^{3} \mathrm{H}(p, n)^{3} \mathrm{He} \\
\mathrm{p}(1.2 \mathrm{MeV})\end{array}$ & $50(\mathrm{QF}=20)$ & 2.0 \\
\hline $\begin{array}{l}\text { Birmingham } \\
\text { (recent work) }\end{array}$ & $\begin{array}{l}{ }^{3} \mathrm{H}(\mathrm{p}, \mathrm{n})^{3} \mathrm{He} \\
\mathrm{p}(1.2 \mathrm{MeV})\end{array}$ & $46(\mathrm{QF}=20)$ & 1.3 \\
\hline Brookhaven & $\begin{array}{l}\text { Reactor } \\
\text { Beam }\end{array}$ & $<20(\mathrm{QF}=10)$ & 0.4 \\
\hline Swansea & ${ }^{252} \mathrm{Cf}$ & $20(\mathrm{QF}=10)$ & 3.4 \\
\hline $\begin{array}{l}\text { McMaster } \\
\text { ( p r e s e n t } \\
\text { study) }\end{array}$ & $\begin{array}{l}\text { Re a c tor } \\
\text { Beam (Beam } \\
\text { Port 4) }\end{array}$ & $\begin{array}{l}43 \\
\text { (Snoopy) }\end{array}$ & 2.8 \\
\hline
\end{tabular}

Table 5.1: Comparison of Hand Doses and Minimum Detection Limits. 


\section{Chapter VI}

\section{Further Work I: Activation Foils}

\subsection{Materials and Method}

The neutron beam from beam port 4 was initially separated into relative flux energy groups in chapter 3, using samples of aluminum, phosphorous and silicon. The three neutron energy groups were thermal, above $1.95 \mathrm{MeV}$, and above $4 \mathrm{MeV}$, respectively. From the results in Table 3.1, the beam was considered to have a strong thermal component. However, no information was obtained on the absolute fluxes between thermal and $1.95 \mathrm{MeV}$. This is an important range for dosimetry since the radiation weighting factors vary greatly in this region (see Fig. 3.2). Furthermore, absolute flux values are necessary in order to calculate a dose equivalent estimate.

A preliminary experiment investigating the neutron flux at low energies was performed using three activation foils. Samples of indium, manganese and gold were irradiated in beam port 4, using the pneumatic "rabbit" transport system to remotely send and retrieve the foils.

Both the indium and manganese samples were wires of approximately $0.6 \mathrm{~mm}$ in diameter. The manganese foil was actually an $80 \%$ manganese- 20 
\% copper (percent of weight) alloy. The gold sample was a thin foil sheet, folded a few times for the irradiation such that the final thickness exposed to the beam was approximately $0.025 \mathrm{~mm}$. All foils were irradiated with and without a cadmium wrapping. The wires were enclosed in a cadmium tube of $2 \mathrm{~mm}$ in outer diameter, and $1 \mathrm{~mm}$ in inner diameter. The gold foil, on the other hand was wrapped in a cadmium sheet, $0.5 \mathrm{~mm}$ in thickness. In order to use the rabbit system, the foils were irradiated in plastic vials (walls $1 \mathrm{~mm}$ in thickness). Care was taken to clean the samples with acetone before wrapping them in cadmium, or before inserting the unwrapped foils in the vials. Acetone will remove deposited impurities, like sodium from the foil contact with skin, whose activations could cause interferences. The foils were backed onto a piece of Scotch tape which held them in the center of the irradiation vials.

The foils were irradiated for 5 minutes, at the rabbit site, and the isotope decays were measured using the calibrated detectors in the NAA center, at the McMaster Nuclear Reactor. The counting time was varied in order to obtain good counting statistics, ie. a percent uncertainty less than 1 $\%$. The manganese wire was also irradiated, for 30 minutes, at the phantom site. For stability, the plastic vial was positioned on the phantom stand, which would reproduce the conditions of the phantom irradiations. The ratio of the activity at the phantom to the activation foil site will help determine how the 
flux changes between the two positions.

\subsection{Initial Experimental Results}

The foils chosen have both a thermal and resonance cross section, as stated in Table $6.1[35,36]$. The corresponding reactions are ${ }^{115} \operatorname{In}(n, \gamma)^{116} \operatorname{In}$, ${ }^{55} \mathrm{Mn}(\mathrm{n}, \gamma){ }^{56} \mathrm{Mn}$, and ${ }^{197} \mathrm{Au}(\mathrm{n}, \gamma)^{198} \mathrm{Au}$. To separate the thermal from the resonance flux, the foils were irradiated with and without a cadmium wrapping. In the study by Swift-Schultz [41], the energy cut off by the cadmium wrapping is related to the cadmium thickness by a linear fit to the data in De Soete [11]:

$$
E(\mathrm{eV})=0.122 C d t(\mathrm{~mm})+0.383
$$

Since the cadmium thickness is $0.5 \mathrm{~mm}$, for all foils, the cut-off energy is calculated to be $0.444 \mathrm{eV}$. This value is well below the resonances of manganese, $337 \mathrm{eV}$, and gold, $4.906 \mathrm{eV}$. However, some neutrons could be removed from the lower tail end of the indium resonance reaction since the resonance energy is $1.457 \mathrm{eV}$ [36]. In this preliminary study, no correction will be made for the lowered indium activity due to the absorbed neutrons.

Thus, the cadmium wrapped foils should only be activated by the 
neutrons with the resonance energies, while the unwrapped foils would give a measure of the thermal and resonance flux combined. The difference in the measured activity of the foils would give the net activity due to thermal neutrons only. The activity of the foils, after the irradiation, is obtained from the efficiency-calibrated counting system, corrected for the transfer time of the samples. With this information, equation 3.7 can provide an absolute value for the thermal flux, and the resonance flux constant with the knowledge of the reaction cross section, half-life of the isotope, irradiation time, and moles of isotope present (see Table 6.1). Thus, the flux equations are:

$$
\phi_{0}=\frac{A}{\sigma_{0} N\left(1-e^{-\lambda}\right)}
$$

or

$$
\phi_{R}=\frac{A}{I_{R} N\left(1-e^{-\lambda t}\right)}
$$

where $\phi_{0}=$ thermal flux

$\phi_{\mathrm{R}}=$ resonance flux constant

$A=$ activity of foil

$\sigma_{0}=$ thermal cross section

$I_{R}=$ resonance integral

$\mathbf{N}=$ number of isotopes to be activated $=\mathbf{n} \times$ Avogadro's number 


\begin{tabular}{|c|c|c|c|c|c|c|c|}
\hline Foil & Half-Life & $\begin{array}{l}\mathrm{t} \\
(\min )\end{array}$ & $\begin{array}{l}\mathrm{n} \\
\left(10^{-3} \text { moles }\right)\end{array}$ & $\begin{array}{l}\text { Activity } \\
\left(10^{3} \mathrm{~Bq}\right)\end{array}$ & $\begin{array}{l}\sigma_{0} \\
\text { (b) }\end{array}$ & $\begin{array}{l}I_{R} \\
(b)\end{array}$ & $\begin{array}{l}\phi_{0} \\
\left(\mathrm{n} / \mathrm{cm}^{2} / \mathrm{s}\right)\end{array}$ \\
\hline${ }^{115}$ In & $54.2 \mathrm{~min}$ & 5 & 0.374 & 38.94 & $162 \pm 0.7$ & & $1.72 \times 10^{7}$ \\
\hline${ }^{115} \mathrm{In}$ in $\mathrm{Cd}$ & & & 0.325 & nil & & $2650 \pm 100$ & nil \\
\hline${ }^{55} \mathrm{Mn}$ & $2.58 \mathrm{hrs}$ & 5 & 0.932 & 6.146 & $13.3 \pm 0.2$ & & $3.72 \times 10^{7}$ \\
\hline${ }^{55} \mathrm{Mn}$ in $\mathrm{Cd}$ & & & 0.932 & nil & & $14.0 \pm 0.3$ & nil \\
\hline${ }^{197} \mathrm{Au}$ & $2.70 \mathrm{~d}$ & 5 & 0.505 & 0.9818 & $98.65 \pm 0.09$ & & $3.67 \times 10^{7}$ \\
\hline${ }^{197} \mathrm{Au}$ in $\mathrm{Cd}$ & & & 0.531 & nil & & $1550 \pm 28$ & nil \\
\hline $\begin{array}{l}\text { At } \\
\text { Ph a n tom } \\
\text { Site } \\
{ }^{55} \mathrm{Mn}\end{array}$ & $2.58 \mathrm{hrs}$ & 30 & 0.932 & 6.809 & $13.3 \pm 0.2$ & & $7.26 \times 10^{6}$ \\
\hline
\end{tabular}

Table 6.1: Neutron Flux from Activation Foil Data. 


$$
\begin{aligned}
& n=\text { number of moles of isotope to be activated } \\
& t=\text { duration of irradiation } \\
& \lambda=\text { decay constant of activated isotope }
\end{aligned}
$$

It is assumed in this experiment that the plastic vials, encasing the foils, do not distort the neutron beam, by absorbing or scattering the neutrons striking it. To verify this assumption a foil could be lowered manually, at the activation foil site in the beam port, taped to a thin aluminum backing, for instance. A thin backing should not cause a significant backscatter problem. The flux obtained with or without the plastic vial could thus be compared.

From the results in Table 6.1, the beam is observed to be almost exclusively thermal. No activation was measured in any of the cadmium wrapped foils, implying that there appears to be no significant resonance neutron flux with energies above even the lowest resonance, ie. $1.457 \mathrm{eV}$, for indium. However, an unmeasurable activation of the cadmium wrapped foils could be occurring. Due to the fact that the foils have a low mass, and that few neutrons will be present in the specific resonance energy ranges, the quantity of activations may be too small to be detectable. It must also be noted that there is no information on the neutron flux between thermal $(0.025$ $\mathrm{eV}$ ) and the cadmium cut-off energy of $0.444 \mathrm{eV}$.

It is therefore assumed that the activity measured in the foils with no cadmium wrapping is due only to thermal neutrons. From equation 6.2 , the 
thermal neutron flux is measured, and its average value for this study is (3.04 $\pm 0.88) \times 10^{7} \mathrm{n} / \mathrm{cm}^{2} / \mathrm{s}$, at the activation foil position. The flux measured with the indium foil is noted to be lower than the two other measurements. Further foils should be activated to determine if this difference is significant, or is due to the foil not being aligned with the beam.

The manganese foil was also irradiated at the phantom position. The neutron flux measured at this position is observed to be lower than at the activation foil site. Theoretically, the flux at the activation foil position should decrease as the square of the ratio of the distance between the two sites and the source. Since the distance between the two positions is approximately 120 $\mathrm{cm}$ and the activation foil site itself is $322 \mathrm{~cm}$ from the beam source, the expected flux at the phantom position, using the manganese foil, should be about $\left(2.0 \times 10^{7}\right) \mathrm{n} / \mathrm{cm}^{2} / \mathrm{s}$. This calculated estimate is somewhat larger than the measured value of $\left(7.26 \times 10^{6}\right) \mathrm{n} / \mathrm{cm}^{2} / \mathrm{s}$. The difference between the calculated and experimental flux could be due to the manganese foil not being placed directly in the beam path, at the phantom position. For this preliminary experiment, the ratio of the measured flux at the phantom to the activation position is calculated to be 0.195 .

Further foils, possibly with larger masses, should be activated to confirm the absence of resonance neutron. However, from the present information, the beam from beam port 4 appears to be mainly thermalized, 
with a negligible resonance component. Thus, a dose equivalent value can be calculated, using the fluence to dose equivalent conversion factors [21]. For thermal neutrons, a fluence of $26 \mathrm{n} / \mathrm{cm}^{2} / \mathrm{s}$ converts to a dose equivalent of 1 $\mu \mathrm{Sv} / \mathrm{hr}$. For the average neutron flux, converted to the phantom site, and a 3 minute irradiation, the dose equivalent to the hand would be $11.4 \mathrm{mSv}$. Note that the quality factors used in the conversion factor are based on ICRP 26 [23], in order to permit comparison with the Snoopy results. In this comparison, the dose equivalent value obtained from the activation foils is observed to be considerably smaller than that measured using the Snoopy monitor. This perhaps implies that the monitor's estimate of dose is actually an overestimation, due to the assumption that the ratio of cross sectional areas between Snoopy and the beam remains the same along the length of the cave. Furthermore, the dose equivalent estimate from the activation foils does not take into consideration the presence of even a small resonance component. Since neutrons in this energy range have much larger quality factors than thermal neutrons, a minimal quantity could give a non-negligible dose. Fast neutrons from the fission spectrum, measured in Chapter 3, are also not included in the activation foil dose equivalent estimate. Thus, this estimate is offered as a lower limit to the actual hand dose equivalent value. 


\section{Chapter VII}

\section{Further Work II: Phantom Irradiation}

\subsection{Phantom Improvements}

The major improvement to be made to the hand phantoms is a reduction in their aluminum impurity. From Chapter 4, it was established that there existed a significant aluminum contamination in the bone ash. Since the resin matrix seemed to be aluminum free, further phantoms could be resin-based. The problem lies in finding a bone ash substitute. It was attempted to use calcium phosphate, $\mathrm{Ca}_{3}\left(\mathrm{PO}_{4}\right)_{2}$, as a source of calcium for the hand phantoms. This powder is a high purity laboratory-type chemical, and should be devoid of aluminum impurities. When mixed with resin however, the matrix never set. There are two plausible explanations for this observation. First, since the density of calcium phosphate is low, a large volume of the chemical needed to be added to the resin in order to obtain $15 \mathrm{~g}$ of calcium (physiological hand concentration [22]). Thus, perhaps this large volume prevented the 400 to 500 $\mathrm{ml}$ of resin to bind together. The second explanation could be that the chemical itself interacted with the catalyst such that it was rendered inert. 
Whichever postulated theory is true, the fact remains that calcium phosphate can not be used to create resin-based phantoms. Another "aluminum-free" calcium and phosphorous source must be found, or perhaps the calcium phosphate could be used with a different substrate.

The bone ash should be sent for some form of chemical analysis in order to determine its actual aluminum content, with more precision than was able to be obtained in this study. This would improve the accuracy of the shift in the calibration curve, in Figure 4.5. However, the fact would remain that measurements on the present set of phantoms involve detecting small added aluminum changes over the large impurity content.

In a third generation of phantoms, the actual shape of the phantoms should be varied. In order to improve the counting geometry, the new phantoms should be flatter, resembling a flat hand instead of a fist, as is the case in the second generation. The detectors could thus be brought closer together since a smaller space would be needed for insertion of the phantoms. These improvements would serve to bring the system nearer to a $4 \pi$ geometry, maximizing the counts detected.

\subsection{Neutron Sources}

For In Vivo measurements of aluminum, by neutron activation analysis, 
the irradiation modality should have a high thermal neutron flux. Beam Port 4 was found to display these characteristics. As observed in Section 4.3, little interference is obtained from the presence of phosphorous, guaranteeing that the major fraction of the area measured at $1.78 \mathrm{MeV}$ peak is due to "true" aluminum. Furthermore, the initial results from the activation foils suggest that the beam is mainly thermal. Thus, for "on site" measurements, this reactor-based source would be a more than adequate modality. Further work would be needed to develop sufficient shielding for patient measurements, in order to maintain the whole body exposure from the beam at a minimum.

An accelerator-based neutron source could also be a feasible alternative if more time could be obtained on the $\mathrm{KN}$-accelerator, in order to perform pilot experiments. The accelerator has the advantage of producing neutrons with a maximum energy below the threshold for interference reactions, and is capable of emitting a sufficiently high flux for hand measurements (see Sect. 3.1). The Birmingham study [17] has previously demonstrated that an accelerator-based modality can be used to obtain a low minimum detection limit, while delivering a low dose equivalent. A further benefit of this neutron source comes from the fact that it could be transported to certain sites of interest, if a mobile accelerator is used. A case of interest is the country of Guam where a disease resembling an early form of Alzheimer's disease is encountered. Other sites would also include factories dealing in the 
production, or in the usage, of aluminum where bone burdens could be correlated to years worked in the aluminum environment. Measurements could also be related to cognitive and neurological tests, as performed in the group of miners [39], to determine any possible correlation to the aluminum exposure.

\subsection{Dosimetry}

Since the dosimetry aspect of this study was only explored in a very preliminary fashion, considerable work remains to be done. Firstly, as stated in Section 6.2, further activation foils could be irradiated in beam port 4 in order to verify that the resonance spectrum is negligible. Furthermore, threshold samples, as in Chapter 3, could give information on the proportion of neutrons in the fission spectrum. From this pertinent information, a better estimate of the dose equivalent could be calculated using the tabulated fluence to dose conversion factors. Knowledge of the fluxes at the various energies present would be necessary to construct appropriate shielding for patient measurements. A ${ }^{3} \mathrm{He}$ spectrometer could also be used to obtain a neutron energy spectrum of this beam port, as in the Birmingham study [14].

Microdosimetric techniques could be used to directly measure the dose delivered to a phantom, due to the irradiation procedure. This process uses a 
tissue equivalent proportional counter, where the walls of a Bragg-Gray cavity sample a charged particle spectrum. The recoil species, being protons for a neutron irradiation, must have enough energy to cross the cavity, or at least only a small number of recoil particles must begin or end in the cavity. The Birmingham study [18] used a microdosimeter with a $1.3 \mathrm{~cm}$ diameter spherical cavity, filled with methane based tissue equivalent gas. A low gas pressure was used in order to obtain a simulated tissue diameter of $2 \mu \mathrm{m}$. The advantage of this method over Snoopy dose estimates is that microdosimetry is more accurate for a field with low neutron energies [17]. However, for neutron energies below $500 \mathrm{keV}$, the recoil proton range is short such that the approximation to a Bragg-Gray cavity breaks down. This situation can be somewhat rectified by lowering the gas pressure inside the cavity. Further experiments need however to be performed. Another advantage microdosimetry holds over the Snoopy-type monitor is that it also measures the dose due to photons, inevitably present in the beam. Once a dosimetry system is established, experiments can investigate an optimal irradiation time that will minimize the dose without compromising a low minimum detection limit.

With these improvements, and most probably a few subsequent ones, steps can be taken towards developing a facility for In Vivo bone aluminum measurements. This system should detect low (normal) levels of aluminum, while delivering a small equivalent dose to the patient, relative to background. 


\section{REFERENCES AND BIBLIOGRAPHY}

[1] Ashton, J.F., Laura, R.S., "Aluminum and Health, The Risks of Dietary Aluminum"; Search, 20, 6, pp.180-2, 1989.

[2] Barker, J. et al., "Development of ${ }^{26} \mathrm{Al}$ Accelerator Mass Spectrometry for Biological and Toxilogical Applications"; Nucl. Instr. and Meth. in Phys. Research, B52, pp.540-3, 1990.

[3] Bevington, P.R. and Robinson, D.R., Data Reduction and Error Analysis for the Physical Sciences, Second Edition, U.S.A: McGraw-Hill, Inc., pp.161-6, 1992.

[4] Bogdanovich, E. et al., "Non-Destructive Bone Aluminum Assay by Neutron Activation Analysis"; 164, 5, pp.293-302, 1992.

[5] Chettle, D.R., "Aluminum Measurements in Peripheral Bone"; Internal Communication, McMaster University, 1992.

[6] Coburn, J.W. and Norris, K.C., "Diagnosis of Aluminum-Related Bone Disease and Treatment of Aluminum Toxicity with Desferrioxamine"; Semin. in Nephrol., 6, p. 12, 1986.

[7] Crapper, D.R. et al., "Intranuclear Aluminum Content in Alzheimer's Disease, Dialysis Encephalopathy, and Experimental Aluminum Encephalopathy"; Acta Neuropathol.(Ber.), 50, pp. 19-24, 1980.

[8] Crapper McLauchlan, D.R. et al., "Intramuscular Desferrioxamine in Patients with Alzheimer's Disease"; The Lancet, 337, pp. 1304-8, 1991.

[9] Day, J.P. et al., "Aluminum Absorption Studied by ${ }^{26} \mathrm{Al}$ Tracer"; The Lancet, $\underline{337}$, p.1345, 1991.

[10] Denny, J.J. et al., "The Prevention of Silicosis by Metallic Aluminum, II"; Can. Med. Assoc. J., 40, 3, pp. 213-28, 1939. 
[11] De Soete, D. et al., Neutron Activation Analysis. Chemical Analysis, Edited by P.J. Elving and I.M. Kolthoff, New York: John Wiley and Sons Ltd., $\underline{34}$, p.40, 1972.

[12] Eastwood, J.B. et al., "Aluminum Deposition in Bone after Contamination of Drinking Water Supply"; The Lancet, $\underline{336}$, pp.462-4, 1990.

[13] Ellis, K.J. et al.,"In Vivo Aluminum Monitoring of Skeletal Aluminum Burden in Patients with Renal Failure"; J. of Radioanal. and Nucl. Chem., Articles, 124, 1, pp. 85-95, 1988.

[14] Fulton, B. and Jeffrey, E.H., "Absorption and Retention of Aluminum from Drinking Water, 1. Effect of Citric and Ascorbic Acids on Aluminum Tissue Levels in Rabbits"; Fund. and Applied Toxic., 14, pp.788-96, 1990.

[15] Gilli, P. et al., "Is Serum Aluminum Monitoring Useful in Evaluating Aluminum Intoxication?"; The Lancet i, p.656, 1983.

[16] Green, S. and Bradley, D., "Bone Aluminum Measurements, A Summary of the January 1992 Dynamitron Run"; Internal Report, Birmingham University, 1992.

[17] Green, S. et al., "Characteristics of an Accelerator Based System for In Vivo Aluminum Measurement in Peripheral Bone"; Preprint from In Vivo Body Composition Studies Conference, 1992.

[18] Green, S. and Chettle, D.R., "A Feasibility Study of the In Vivo Measurements of Aluminum in Peripheral Bone"; Phys. Med. Biol., 37, 12, pp. 2287-96, 1992.

[19] Goodman, W.G. and Leite Duarte, M.E., "Aluminum: Effects on Bone and Role in the Pathogenesis of Renal Osteodystrophy"; Miner. Electrolyte Metab., 17, pp.221-32, 1991.

[20] Hamdy, R.C., "Aluminum Toxicity and Alzheimer's Disease"; Post Graduate Medicine, Alzheimer's disease, 88, 5 pp.239-40, 1990.

[21] International Commission on Radiological Protection, "Data for the Protection Against Ionizing Radiation from External Sources"; 
Publication 21, Pergamon Press, Oxford, 1971, pp. 52-3.

[22] International Commission on Radiological Protection, "Report on the Task Group of Reference Man"; Publication 23, Pergamon, Oxford, 1975.

[23] International Commission on Radiological Protection, "Recommendation of the ICRP"; Annals of the ICRP, Publication 26, 1, 3, Pergamon, Oxford, 1977.

[24] International Commission on Radiological Protection, "1990 Recommendations of the ICRP"; Annals of the ICRP, Publication 60, 21, 1-3, Pergamon, Oxford, 1990.

[25] Joglar, F.M. et al., "Experience with Aluminum-Associated Bone Disease in End-Stage Renal Disease patients"; Transplantation Proc., 23, 2, pp. 1823-4, 1991.

[26] Kobayashi, K. et al., " ${ }^{26} \mathrm{Al}$ tracer Experiment by Accelerator Mass Spectrometry and its Application to the Studies for Amyotrophic Lateral Sclerosis and Alzheimer's Disease. I"; Proc. Japan Acad., 66, Ser. B, 101, pp. 189-92, 1990.

[27] Kennett, T.J., assembling of analysis program, internal communication, McMaster University, 1993.

[28] Knoll, G.F.,Radiation Detection and Measurement, Second Edition,Toronto: John Wiley and Sons, Inc., 1989, pp.313, and 398.

[29] Kruck, T.P.A. et al., "Suppression of Desferrioxamine mesylate Treatment- Induced Side Effects by Coadministration of Isonizid in a Patient with Alzheimer's Disease subject to Aluminum Removal by Ionspecific Chelation"; 48, 4, pp. 439-46, 1990.

[30] Landsberger, S. and Arendt, A.M., "Non-Destructive Determination of Aluminum in Biological Reference Samples Using Neutron Activation Analysis"; J. Radioanal. Nucl. Chem., Letters, 137, 6, pp. 443-54, 1989.

[31] Martyn, C.N. et al., "Geographical Relation Between Alzheimer's Disease and Aluminum in Drinking Water"; The Lancet i, 59, 1989. 
[32] McLane, V. et al., Neutron Cross Sections: Neutron Cross Section Curves, 2, San Diego: Academic Press, Inc., 1988.

[33] Moon, J. et al., "Vitamin D and Aluminum Absorption"; Can. Med. Assoc. J., 147, 9, pp.1308-9, 1992.

[34] Morgan, W.D. et al., "Development of a Technique to Measure Bone Aluminum In Vivo Using a ${ }^{252}$ Cf Neutron Source"; Advances in In Vivo Body Composition Studies, Edited by S. Yasumura et al., Plenum Press, New York, pp. 437-8, 1990.

[35] Mughabghab, S.F., Neutron Cross Sections: Neutron Resonance Parameters and Thermal Cross Sections, Part B: $\mathrm{Z}=61$ to 100,1 , New York: Academic Press Inc., 1984.

[36] Mughabghab, S.F., Neutron Cross Sections: Neutron Resonance Parameters and Thermal Cross Sections, Part A: $Z=1$ to 60,1 , New York: Academic Press Inc., 1981.

[37] Neri, L.C. and Hewitt, D., "Aluminum, Alzheimer's Disease, and Drinking Water"; The Lancet, 338, p. 390, 1991.

[38] Nicar, M.J. et al., "Brain and Bone Aluminum: A Comparison of Aluminum Intake in Rats"; Environ. Toxic. and Chem., 11, pp. 1331-6, 1992.

[39] Rifat, S.L. et al., "Effects of Exposure of Miners to Aluminum Powder"; The Lancet ii, 1162, 1990.

[39b] Segre, E., Nuclei and Particles, Second Edition, Don Mills, Ont.: Addison-Wesley Publishing Company, Inc., p. 586, 1977.

[40] Sokolowski, T.W., Neutron Dose Measurements by Means of a Tissue Equivalent Proportional Counter, McMaster Univertsity, pp. 11121, 1989.

[40b] Snedicor, G.W. and Cochran, W.G., Statistical Methods, Sixth Edition, Iowa: The Iowa State University Press, pp.104-5, 1967.

[41] Swift-Schultz, C.L.,Neutron Dose-Equivalent Estimation for Rat Whole- 
Body Calcium Measurement, McMaster University, pp. 64-79, 1985.

[42] Tracerlab., NP-1 Portable Neutron Monitor, Operating and Maintenance Instructions, (Part No. A245890), pp. 1-6, 1966.

[43] Weidner, R.T. and Sells, R.L., Elementary Modern Physics, Third Edition, Boston: Allyn and Bacon, Inc., pp. 357-60, 1980.

[44] Williams, E.D. et al., "Whole Body Aluminum in Chronic Renal Failure and Dialysis Encephalopathy"; Clinical Nephro., 14, 4, pp. 198$200,1980$.

[45] Wills, M.R. and Savory, J., "Aluminum Poisoning: Dialysis Encephalopathy, Osteomalacia, and Anemia"; The Lancet ii, pp. 29-33, 1983.

[46] Xu, Z.X. et al., "Mechanism of Aluminum-Induced Inhibition of Hepatic Glycolysis: Inactivation of Phosphofructokinase"; J. of Pharmac. Sci., 254,1, pp. 301-4, 1990. ${ }^{126} \mathrm{Al}$ and Accelerator Mass Spectroscopy- A Biological Application"; Science and Engineering Research Council, Daresbury Lab., Warrington, pp. 23-6, 1991/92. 